Atmos. Chem. Phys., 18, 12141-12159, 2018

https://doi.org/10.5194/acp-18-12141-2018

(C) Author(s) 2018. This work is distributed under

the Creative Commons Attribution 4.0 License.

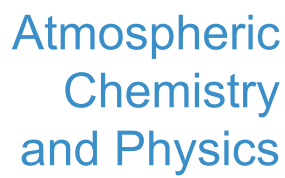

(c) (P)

\title{
Measurement and modeling of the multiwavelength optical properties of uncoated flame-generated soot
}

\author{
Sara D. Forestieri ${ }^{1, \mathrm{a}}$, Taylor M. Helgestad ${ }^{1, \mathrm{a}}$, Andrew T. Lambe ${ }^{2,3}$, Lindsay Renbaum-Wolff ${ }^{2}$, Daniel A. Lack ${ }^{4,5, b}$, \\ Paola Massoli $^{2}$, Eben S. Cross ${ }^{6, c}$, Manvendra K. Dubey ${ }^{7}$, Claudio Mazzoleni ${ }^{8}$, Jason S. Olfert ${ }^{9}$, \\ Arthur J. Sedlacek III ${ }^{10}$, Andrew Freedman ${ }^{2}$, Paul Davidovits ${ }^{3}$, Timothy B. Onasch ${ }^{2,3}$, and Christopher D. Cappa ${ }^{1}$ \\ ${ }^{1}$ Department of Civil and Environmental Engineering, University of California, Davis, CA 95616, USA \\ ${ }^{2}$ Aerodyne Research Inc., Billerica, MA 01821, USA \\ ${ }^{3}$ Chemistry Department, Boston College, Boston, MA 02467, USA \\ ${ }^{4}$ NOAA Earth System Research Laboratory, Boulder, CO 80305, USA \\ ${ }^{5}$ Cooperative Institute for Research of the Environmental Sciences, University of Colorado, Boulder, CO 80305, USA \\ ${ }^{6}$ Department of Civil and Environmental Engineering, Massachusetts Institute of Technology, Cambridge, MA 02139, USA \\ ${ }^{7}$ Los Alamos National Laboratory, Los Alamos, NM 87545, USA \\ ${ }^{8}$ Department of Physics and Atmospheric Sciences Program, Michigan Technological University, Houghton, MI 49931, USA \\ ${ }^{9}$ Department of Mechanical Engineering, University of Alberta, Edmonton, Alberta, Canada \\ ${ }^{10}$ Biological, Environmental and Climate Sciences Department, Brookhaven National Laboratory, Upton, NY 11973, USA \\ ${ }^{a}$ now at: California Air Resources Board, Sacramento, CA 95814, USA \\ ${ }^{b}$ now at: Transport Emissions, Air Quality and Climate Consulting, Brisbane, Australia \\ ${ }^{c}$ now at: Aerodyne Research Inc., Billerica, MA 01821, USA
}

Correspondence: Sara D. Forestieri (sara.forestieri@arb.ca.gov) and Christopher D. Cappa (cdcappa@ucdavis.edu)

Received: 23 March 2018 - Discussion started: 11 April 2018

Revised: 20 July 2018 - Accepted: 24 July 2018 - Published: 22 August 2018

\begin{abstract}
Optical properties of flame-generated black carbon (BC) containing soot particles were quantified at multiple wavelengths for particles produced using two different flames: a methane diffusion flame and an ethylene premixed flame. Measurements were made for (i) nascent soot particles, (ii) thermally denuded nascent particles, and (iii) particles that were coated and then thermally denuded, leading to the collapse of the initially lacy, fractal-like morphology. The measured mass absorption coefficients (MACs) depended on soot maturity and generation but were similar between flames for similar conditions. For mature soot, here corresponding to particles with volume-equivalent diameters $>\sim 160 \mathrm{~nm}$, the MAC and absorption Angström exponent (AAE) values were independent of particle collapse while the single-scatter albedo increased. The MAC values for these larger particles were also size-independent. The mean MAC value at $532 \mathrm{~nm}$ for larger particles was $9.1 \pm 1.1 \mathrm{~m}^{2} \mathrm{~g}^{-1}$, about $17 \%$ higher than that recommended by Bond and Bergstrom (2006), and the AAE was close to unity. Effective, theory-specific com-
\end{abstract}

plex refractive index (RI) values are derived from the observations with two widely used methods: Lorenz-Mie theory and the Rayleigh-Debye-Gans (RDG) approximation. Mie theory systematically underpredicts the observed absorption cross sections at all wavelengths for larger particles (with $x>0.9$ ) independent of the complex RI used, while RDG provides good agreement. (The dimensionless size parameter $x=\pi d_{\mathrm{p}} / \lambda$, where $d_{\mathrm{p}}$ is particle diameter and $\lambda$ is wavelength.) Importantly, this implies that the use of Mie theory within air quality and climate models, as is common, likely leads to underpredictions in the absorption by $\mathrm{BC}$, with the extent of underprediction depending on the assumed $\mathrm{BC}$ size distribution and complex RI used. We suggest that it is more appropriate to assume a constant, size-independent (but wavelength-specific) MAC to represent absorption by uncoated BC particles within models. 


\section{Introduction}

Soot particles, which contain light-absorbing black carbon (BC), are a byproduct of the incomplete combustion of fossil fuels and biomass. These particles affect climate directly by absorbing and scattering solar radiation (Bond et al., 2013) and indirectly by acting as cloud condensation nuclei, especially following chemical processing (Lohmann and Feichter, 2005). Soot particles absorb shortwave radiation and have an overall warming effect on climate. The exact magnitude of the climate impacts of $\mathrm{BC}$ remains uncertain. One estimate puts top-of-the-atmosphere direct forcing by $\mathrm{BC}$ as high as $0.9 \mathrm{~W} \mathrm{~m}^{-2}$, which is comparable in magnitude to that of $\mathrm{CO}_{2}$ (Ramanathan and Carmichael, 2008). Other more recent assessments yield $0.71 \mathrm{~W} \mathrm{~m}^{-2}$ with $90 \%$ uncertainty bounds of 0.08 to $1.27 \mathrm{~W} \mathrm{~m}^{-2}$ (Bond et al., 2013) or 0.61 $[+0.16$ to +1.40$] \mathrm{W} \mathrm{m}^{-2}$ (Wang et al., 2016), while the IPCC suggests a value of $0.40[+0.05$ to +0.80$] \mathrm{W} \mathrm{m}^{-2}$ (Boucher et al., 2013).

One challenge in modeling the optical properties of soot, and of the $\mathrm{BC}$ component in particular, derives from $\mathrm{BC}$ having a complex, fractal-like structure, being an agglomerate of small "spherules" (Medalia and Heckman, 1969). One theory that is commonly used in climate models to calculate BC optical properties is Lorenz-Mie theory (hereafter, Mie theory), which makes the physically unrealistic assumption that soot particles are spherical (Bohren and Huffman, 1983). This theory is widely used in climate models (Bond et al., 2013), in part because it does not require any details about the number of spherules or the arrangement of the spherules within the agglomerate but also because it is compatible with calculations for other spherical aerosol types. A variation on Mie theory, the Rayleigh-Debye-Gans (RDG) approximation, is also often used to model the optical properties of BC (Sorensen, 2001), albeit not by climate models. In RDG, the agglomerate absorption cross section ( $\left.\sigma_{\text {abs }}\right)$ is the product of $\sigma_{\mathrm{abs}}$ for individual spherules and the number of spherules in the agglomerate. As such, RDG neglects spherule-to-spherule interactions, and the mass absorption coefficient (MAC) of an individual spherule is equal to that of the overall particle. (The MAC is the absorption cross section normalized by the particle mass.) There are more complex methods for calculating soot particle optical properties, including the T-matrix method (Mackowski and Mishchenko, 1996) and the discrete dipole approximation (DDA) (Purcell and Pennypacker, 1973), which account for interactions between spherules. Given that these more advanced methods require detailed information on the shape of the soot particles and are computationally intensive, they are not practical for climate models. The derived effective refractive indices used as inputs for these models are theory-specific, and it is necessary to have experimentally constrained effective refractive indices for both RDG and Mie theory if they are to be employed in climate models. For example, Bond et al. (2006) suggested that BC can be described using an
MAC $=7.5 \mathrm{~m}^{2} \mathrm{~g}^{-1}$ at $550 \mathrm{~nm}$ and a complex refractive in$\operatorname{dex}(\mathrm{RI})=1.95-0.79 i$. However, as they show, the maximum MAC calculated from Mie theory using this refractive index is only $7.2 \mathrm{~m}^{2} \mathrm{~g}^{-1}$ over a very narrow range of particle sizes and is much smaller in general, with a value of $4.9 \mathrm{~m}^{2} \mathrm{~g}^{-1}$ in the small particle limit, where RDG applies (assuming $\rho=1.8 \mathrm{~g} \mathrm{~cm}^{-3}$ ). In other words, there can be an inconsistency between the often used MAC and complex RI. This illustrates the need for theory-specific effective refractive index values and a more thorough exploration of the robustness of commonly used optical models.

Our work investigates the ability of two optical models, Mie theory and the RDG approximation, to reproduce observed soot optical properties for particles composed primarily of $\mathrm{BC}$. The observations include light absorption and extinction coefficients of soot particles produced from methane diffusion and ethylene premixed flames, measured over four different studies at multiple wavelengths. The impact of shape on soot particle optical properties is also examined. The soot particles sampled during these studies serve as a proxy for different types of soot particles in the ambient atmosphere. Recommended theory-specific complex RI values for BC-dominated soot particles are provided. However, we ultimately suggest that atmospheric models should consider adopting observationally constrained, wavelengthspecific constant MAC values for BC rather than calculating the optical properties from optical theories.

\section{Experimental: the black carbon studies}

The measurements reported here were made during a series of laboratory intensive studies that took place at Boston College (BC2, BC3, and BC4) in 2008, 2012, and 2015 and Aerodyne Research (BC3+) in 2014. Below, we provide details of soot particle generation and the measurements made. An experimental schematic is provided in Fig. S1 (in the Supplement).

\subsection{Soot particle generation}

Soot particles were produced using two different flame sources and fuel types. During the $\mathrm{BC} 3, \mathrm{BC} 3+$, and $\mathrm{BC} 4$ studies, most experiments were conducted using particles produced from an inverted co-flow diffusion flame operating on methane with a sheath flow mixture of $\mathrm{O}_{2}$ and $\mathrm{N}_{2}$ (Stipe et al., 2005) with a net fuel equivalence ratio $\varphi=0.7 \pm 0.07$; because the diffusion flame entrains sheath oxygen into the methane-rich center flow, a range of $\varphi$ values are accessed, including regions where the local $\varphi$ may be greater than 1 . These are referred to as the "methane diffusion flame" experiments and have been combined into a single dataset since the sampling and generation were similar in all.

During BC2 and for a small number of experiments during $\mathrm{BC} 3+$, particles were produced using a McKenna flat- 
flame burner from the combustion of premixed $\mathrm{C}_{2} \mathrm{H}_{4}$ (ethylene), $\mathrm{O}_{2}$ and $\mathrm{N}_{2}$ with $\varphi=2.0 \pm 0.2$. These are referred to as the "ethylene premixed flame" experiments. Particles were sampled at a nominal height of $5 \mathrm{~cm}$ above the burner during $\mathrm{BC} 3+$ but at a nominal height of $20 \mathrm{~cm}$ above the burner during BC2 (Cross et al., 2010). As such, the results from the two ethylene premixed flame have been kept separate because particles were sampled from the flame differently in the two studies.

The soot particles produced from these two flames exhibited different properties. For example, the organic (OC) mass fraction of the nascent (i.e., freshly emitted and unprocessed) ethylene premixed flame soot particles in BC2 was $\sim 0.26$ (Cross et al., 2010), whereas the OC fraction of nascent methane diffusion flame particles was $<0.01$. Consequently, upon heating to $>200^{\circ} \mathrm{C}$, the per-particle mass of the ethylene premixed flame soot particles decreased while the methane diffusion flame soot particles were unaffected.

The sampling and/or burner conditions were modified during these studies to generate monodisperse soot particles with a volume-equivalent diameter $\left(d_{\mathrm{p}, \mathrm{VED}}\right)$ less than $160 \mathrm{~nm}$. The $d_{\mathrm{p}, \mathrm{VED}}$ is the diameter calculated from the per-particle mass assuming that particles have spherical morphology and the material density of the particles is $1.8 \mathrm{~g} \mathrm{~cm}^{-3}$ (Bond and Bergstrom, 2006; Wu et al., 1997; Mullins and Williams, 1987):

$d_{\mathrm{p}, \mathrm{VED}}=\left(\frac{6 m_{\mathrm{p}}}{1.8 \cdot \pi}\right)^{1 / 3}$,

where $m_{\mathrm{p}}$ is the per-particle mass. For the ethylene premixed flame, sampling closer to the burner surface selected for smaller soot particles; sampling on the centerline over the burner surface vs. off-center may also affect the selected soot particle sizes. For the methane diffusion flame, increasing the fuel dilution $\left(\mathrm{N}_{2}\right)$ fraction generated smaller soot particles (Stipe et al., 2005). These variations in sampling and/or burner conditions likely led to some changes in the particle optical and chemical properties (López-Yglesias et al., 2014). Thus, some of the size-dependent changes observed in particles smaller than $d_{\mathrm{p}, \mathrm{VED}} \sim 160 \mathrm{~nm}$, discussed below, are likely a result of real changes in the particle properties. The extreme case is in the comparison between the soot particles sampled at $5.1 \mathrm{~cm}(\mathrm{BC} 3+)$ and $20.3 \mathrm{~cm}(\mathrm{BC} 2)$ above the ethylene premixed flame burner surface.

\subsection{Particle processing}

The soot particles were subjected to various kinds of physical and chemical processing and were selected according to their mobility diameter after processing but prior to sampling for optical and chemical property measurements. Particles sizeselected with no processing are termed nascent soot particles. For some experiments, nascent particles were passed through a thermal denuder in which they were heated to $270^{\circ} \mathrm{C}$ for $\sim 5 \mathrm{~s}$. Such particles are termed nascent-denuded soot particles. (A summary of terminology is provided in Table S1.) For other experiments, nascent particles were first coated and then thermo-denuded. Coating materials included either dioctyl sebacate (DOS, $\mathrm{C}_{x} \mathrm{H}_{y} \mathrm{O}_{x} ; \mathrm{BC} 2, \mathrm{BC} 3$, and $\mathrm{BC} 3+)$, sulfuric acid $\left(\mathrm{H}_{2} \mathrm{SO}_{4}\right.$; all studies), or secondary organic aerosol from $\alpha$-pinene photooxidation (SOA; BC4). These particles are referred to as coated-denuded. Literature results indicate that the thermo-denuding of particles coated with or composed of these materials leads to essentially complete evaporation of the non-refractory material (Cappa and Wilson, 2011; Huffman et al., 2008), confirmed by measurements from BC2 (Cross et al., 2010).

For DOS coatings, the nascent particles were first sizeselected, the monodisperse nascent particles were coated, and the coated particles were subsequently denuded. This is referred to as a forward-coating experiment. For either $\mathrm{H}_{2} \mathrm{SO}_{4}$ or SOA coatings, polydisperse nascent soot particles were first coated, then size-selected, and finally denuded. This is referred to as a reverse-coating experiment. This difference in methodology decreased the extent of homogenous nucleation of pure $\mathrm{H}_{2} \mathrm{SO}_{4}$ and $\mathrm{SOA}$ particles by providing additional soot surface area to act as a condensation sink, and any nucleated particles were further excluded during the size selection. However, the reverse method led to broader size and mass distributions in the denuded soot cores. The typical geometric standard deviation of the per-particle mass distributions for forward-coating experiments was 1.3, while for reverse-coating experiments it ranged from around 1.3 to 2 .

For $\mathrm{BC} 2, \mathrm{BC} 3$, and $\mathrm{BC} 3+$, soot particles were coated in a heated section of tubing containing either DOS or $\mathrm{H}_{2} \mathrm{SO}_{4}$, which cooled and condensed onto soot particles after exiting the heated section of tubing. For BC4 experiments, soot particles were coated with $\alpha$-pinene SOA and $\mathrm{H}_{2} \mathrm{SO}_{4}$ that were generated in a potential aerosol mass (PAM) oxidation flow reactor (Lambe et al., 2011). In the PAM reactor, $\mathrm{O}_{3}$ was photolyzed by UV lamps at $\lambda=254 \mathrm{~nm}$ to produce $\mathrm{O}\left({ }^{1} \mathrm{D}\right) \mathrm{rad}$ icals, which then reacted with water $(\mathrm{RH}=25 \%-30 \%)$ to produce $\mathrm{OH}$ radicals. Low-volatility products were formed via the reaction between $\mathrm{OH}$ and $\alpha$-pinene, which condensed onto the soot particles. Similarly, $\mathrm{H}_{2} \mathrm{SO}_{4}$ was formed through the reaction of $\mathrm{SO}_{2}$ and $\mathrm{OH}$ radicals.

Particles were size-selected according to their mobility diameter $\left(d_{\mathrm{m}}\right)$ using a differential mobility analyzer (DMA; TSI model 3080) with a sheath-to-sample flow ratio of $5: 1$, yielding a resolution of $\sim \pm 20 \%$ of the set point in terms of mobility. During BC4, particles were mass-selected with a centrifugal particle mass analyzer (CPMA; Cambustion Ltd.), in addition to being size-selected using a DMA. Particles sampled into the DMA or CPMA first passed through a neutralizer, which imparts an equilibrium charge distribution to the particles. The DMA selects particles according to their electrical mobility, which is dependent upon the number of charges per particle. Particles with more than one charge are larger than those with a single charge, and the presence of these larger particles can confound the interpretation of 
optical property measurements. Altering the burner and sampling conditions for both flame types minimized the number of these multiply charged particles during the experiments, and in some cases their concentrations were effectively zero. However, for some experiments, their concentrations were non-zero. The method used to account for the multiply charged particles is discussed below.

\subsection{Instrumentation}

A wide range of instruments was employed to characterize the soot particle size, mass, composition and optical properties. Not all instruments were deployed for all studies, summarized in Table S2.

\subsubsection{Size and mass}

Particle mobility size distributions were measured using a scanning mobility particle sizer (SMPS; TSI model 3936). Particles sampled into the SMPS were passed through a neutralizer, which imparts a new equilibrium charge distribution to the particles. This (re)neutralization step shifts the charge distribution of the monodisperse particles imparted by the size-selection DMA to a new equilibrium state. For particles with mobility diameters $200-300 \mathrm{~nm}$ (typical of these studies), the number concentration ratio between particles with +1 charge to those with a greater number of charges selected by the DMA is $\sim 2-2.5$ at equilibrium. Thus, after (re)neutralization, the majority of the particles that were in a +2 state coming out of the DMA are sized in the SMPS in their +1 state. This allows for the quantitative determination of the fraction of particles that had charge states of +1 , $+2,+3$, etc., when selected by the DMA. The information is used to correct the optical measurements for contributions from larger, multiply charged particles for $\mathrm{BC} 2, \mathrm{BC} 3$, and $\mathrm{BC} 3+$.

Particle mass distributions were measured using a CPMA. Particle number concentrations were measured using a condensation particle counter (CPC; TSI Inc.) and using a mixing CPC (MCPC, BMI model 1710). The two particlecounting instruments were placed at different points in the flow path to estimate and account for losses in the transfer lines between instruments. All CPC number concentrations agreed within $\pm 5 \%$.

\subsubsection{Composition}

Particle composition was characterized online using a soot particle aerosol mass spectrometer (SP-AMS; Aerodyne Research, Inc.) (Onasch et al., 2012) and a compact time-offlight aerosol mass spectrometer (c-ToF-AMS; Aerodyne Research, Inc.) (Canagaratna et al., 2007). The SP-AMS measured concentrations of refractory $\mathrm{BC}$ and the associated refractory and non-refractory coatings in $\mathrm{BC}$-containing particles. The c-ToF-AMS measures concentrations of only nonrefractory materials, which include particulate organic matter
(POM) and some inorganic salts $\left(\mathrm{NH}_{4}^{+}, \mathrm{SO}_{4}^{2-}, \mathrm{NO}_{3}^{-}\right)$. Both instruments allow for the determination of mass-weighted particle size distributions as characterized by the vacuum aerodynamic diameter $\left(d_{\mathrm{p}, \mathrm{va}}\right)$. Particles were also collected on quartz-fiber filters for offline thermal-optical analysis (Chow et al., 2004), from which the relative abundances of $\mathrm{OC}$ and elemental carbon (EC) are determined.

During BC4, refractory black carbon mass was quantified with a single particle soot photometer (SP2; Droplet Measurement Technologies). The SP2 heats up the soot particles with an Nd:YAG laser and quantifies the incandescence emission as the particle evaporates. The incandescence signal from the instrument was calibrated using DMA size-selected fullerene soot (Alfa Aesar Lot L18U002) (Laborde et al., 2012). The mass distributions from the SP2 were used to determine contributions from multiply charged particles during BC4.

\subsubsection{Optical properties}

Particle optical properties were characterized using multiple instruments. Three different photoacoustic spectrometers (PASs) were used during the various studies to measure particulate light absorption coefficients $\left(b_{\mathrm{abs}}\right)$. During BC2, a custom-built PAS from the National Oceanic and Atmospheric Administration (NOAA) operating at $\lambda=532 \mathrm{~nm}$ was deployed (Lack et al., 2006). Also, during BC2, a commercial three-wavelength particle absorption soot spectrometer (PASS-3; DMT, Inc.) operating at $\lambda=405,532$, and $781 \mathrm{~nm}$ was deployed by Los Alamos National Laboratory (LANL) (Flowers et al., 2010). The results from the different PAS instruments for $\mathrm{BC} 2$ are compared in Cross et al. (2010). During BC3, BC3+, and BC4, a custom-built PAS from the University of California, Davis (UCD), operating at $\lambda=405$ and $532 \mathrm{~nm}$, was deployed (Lack et al., 2011; Cappa et al., 2012). Light absorption was also measured during $\mathrm{BC} 3, \mathrm{BC} 3+$, and $\mathrm{BC} 4$ at $\lambda=630 \mathrm{~nm}$ using a commercial cavity-attenuated phase-shift single-scatter albedo spectrometer (CAPS PMSSA; Aerodyne Research, Inc.). The CAPS $\mathrm{PM}_{\mathrm{SSA}}$ measures particulate light absorption as the difference between the measured light extinction $\left(b_{\text {ext }}\right)$ and scattering $\left(b_{\text {sca }}\right)$ coefficients, whereas the PAS instruments measure light absorption directly. The CAPS extinction measurement has been previously described (Massoli et al., 2010). The CAPS PMSSA measures $b_{\text {sca }}$ using an integrating nephelometer, corrected for the finite viewing angle of the detector, i.e., truncation correction (Onasch et al., 2015b). The truncation correction at $630 \mathrm{~nm}$ was determined to be $<1 \%$ at $630 \mathrm{~nm}$ for particles smaller than $300 \mathrm{~nm}$, increasing to $<5 \%$ for particles smaller than $800 \mathrm{~nm}$. Light extinction coefficients were measured at $\lambda=532 \mathrm{~nm}$ during $\mathrm{BC} 2$ using the NOAA cavity ring-down (CRD) spectrometer and at $\lambda=405$ and $532 \mathrm{~nm}$ during $\mathrm{BC} 3, \mathrm{BC} 3+$, and $\mathrm{BC} 4$ using the UCD CRD spectrometer (Langridge et al., 2011). Light extinction coefficients were also determined during BC2 at $\lambda=405,532$, 
and $781 \mathrm{~nm}$ using the PASS-3 instrument, which, like the CAPS PMSSA, incorporates an integrating nephelometer to measure $b_{\text {sca }} ; b_{\text {ext }}$ is determined as the sum of $b_{\text {abs }}$ and $b_{\text {sca }}$.

Absorption and extinction cross sections were determined for the size-selected particles as

$\sigma_{\mathrm{abs}}\left(\mathrm{m}^{2}\right.$ particle $\left.^{-1}\right)=\frac{b_{\mathrm{abs}}}{N_{\mathrm{p}}}$,

$\sigma_{\text {ext }}\left(\mathrm{m}^{2}\right.$ particle $\left.^{-1}\right)=\frac{b_{\text {ext }}}{N_{\mathrm{p}}}$,

where $N_{\mathrm{p}}$ is the measured particle number concentration. Additional parameters of interest that can be calculated from the measurements are the wavelength-dependent mass absorption and extinction coefficients, MAC and MEC, respectively, defined as

$\operatorname{MAC}\left(\mathrm{m}^{2} \mathrm{~g}^{-1}\right)=\frac{b_{\text {abs }}}{N_{\mathrm{p}} \times m_{\mathrm{p}}}$,

$\operatorname{MEC}\left(\mathrm{m}^{2} \mathrm{~g}^{-1}\right)=\frac{b_{\text {ext }}}{N_{\mathrm{p}} \times m_{\mathrm{p}}}$,

where $m_{\mathrm{p}}$ is the per-particle mass. The combination of the absorption and extinction cross sections allows for the calculation of single-scatter albedo (SSA), defined as

$\mathrm{SSA}=1-\frac{\sigma_{\mathrm{abs}}}{\sigma_{\mathrm{ext}}}$.

The SSA characterizes the fraction of extinction that is due to scattering. The wavelength-dependence of absorption is characterized by the semiempirical parameter, the absorption Ångström exponent, defined as

$\mathrm{AAE}=\frac{\ln \left(\sigma_{\mathrm{abs}, 2} / \sigma_{\mathrm{abs}, 1}\right)}{\ln \left(\lambda_{1} / \lambda_{2}\right)}$,

where $\lambda$ is wavelength and the subscript 1 and 2 indicate two different wavelengths.

\section{Data analysis}

\subsection{Mass mobility exponent}

One measure of particle shape is the mass mobility exponent $\left(D_{\mathrm{f}, \mathrm{m}}\right)$ (Park et al., 2003):

$m_{\mathrm{p}}=C \cdot d_{\mathrm{m}}^{D_{\mathrm{f}, \mathrm{m}}}$,

where $C$ is the proportionality constant. (The mass mobility exponent, $D_{\mathrm{f}, \mathrm{m}}$, differs from the fractal dimension, $D_{\mathrm{f}}$, as discussed by Sorensen (2011).) Values of $D_{\mathrm{f}, \mathrm{m}}$ for atmospheric particles typically range from 2.0 to 3.0, with lower values being characteristic of more "lacy" soot and higher values of more compacted soot. $D_{\mathrm{f}, \mathrm{m}}$ values were obtained for nascent and coated-denuded soot particles by fitting a power law function to a graph of $m_{\mathrm{p}}$ vs. $d_{\mathrm{m}}$.

\subsection{Refractive index retrieval}

Effective complex refractive index values (RI; $n=m+k_{i}$ ) for the soot particles were determined using two methods: (1) spherical particle Mie theory and (2) RDG approximation. For the refractive index, $m$ is the real component and $k_{i}$ is the imaginary component. In Mie theory, particle cross sections are calculated assuming spherical particles with a homogenously uniform complex refractive index. The calculated cross section is the product of the calculated absorption or extinction efficiency ( $Q_{\text {abs }}$ or $Q_{\text {ext }}$ ) and the geometric particle cross section $\left(=\pi \cdot\left[d_{\mathrm{p}} / 2\right]^{2}\right.$, where $d_{\mathrm{p}}$ is the particle diameter). Here, the particle diameter used in the calculations is the measured $d_{\mathrm{p}, \mathrm{VED}}$, as determined from the CPMA perparticle mass measurements and assuming a material density for BC of $1.8 \mathrm{~g} \mathrm{~cm}^{-3}$. In the RDG approximation (Sorensen, 2001), the absorption cross sections are calculated as

$\sigma_{\text {abs,RDG }}=N_{\text {spherule }} \sigma_{\text {abs,spherule }}$,

where $N_{\text {spherule }}$ is the number of spherules comprising a particle and $\sigma_{\text {abs,spherule }}$ is the absorption cross section calculated for a single spherule using Mie theory. Here, we have assumed that $N_{\text {spherule }}=m_{\mathrm{p}} / m_{\text {spherule }}$, where $m_{\mathrm{p}}$ is the measured per-particle mass and $m_{\text {spherule }}$ is the mass of an individual spherule with $d_{\mathrm{p}}=20 \mathrm{~nm}$ (ethylene premixed flame) (Cross et al., 2010) or $d_{\mathrm{p}}=37 \mathrm{~nm}$ (methane diffusion flame) (Ghazi et al., 2013), again assuming a material density of $1.8 \mathrm{~g} \mathrm{~cm}^{-3}$.

Optimal (best-fit), theory-specific values of $m$ and $k$ were established by comparing the size-dependent observations of $\sigma_{\text {abs }}$ to calculations from either Mie theory or the RDG approximation by varying these parameters over the ranges $1.3<m<2.2$ and $0.1<k<1.5$ and determining the minimum value of the reduced chi-square statistic:

$\chi_{\text {red }}^{2}=\frac{1}{N-1} \sum_{j}\left[\frac{\left(\sigma_{\mathrm{abs}}^{j}-\sigma_{\mathrm{abs}, \mathrm{calc}}^{j}\right)^{2}}{\varepsilon_{\mathrm{abs}}^{2}}\right]$,

where $\sigma_{\text {abs }}^{j}$ is the measured absorption cross section, $\sigma_{\text {abs, Mie }}^{j}$ is the calculated absorption cross section, $N$ is the number of points, and $\varepsilon_{\mathrm{abs}}$ is the estimated uncertainty, which accounts for both instrumental uncertainties plus the uncertainty associated with contributions from multiply charged particles. Individual fits were performed for each wavelength for each flame type. The methane diffusion flame soot data collected during different studies were treated as one dataset, whereas the ethylene premixed flame soot data collected during the different studies were kept separate due to the sampling differences described above.

\subsection{Accounting for multiply charged particles}

All absorption and extinction coefficient measurements were corrected for contributions from doubly charged (Q2) particles. This correction leads to a decrease in the measured 
absorption and extinction coefficients. Here, an approach is taken where the fraction of absorption or extinction from $\mathrm{Q} 2 \mathrm{~s}$ ( $f_{\text {abs,Q2 }}$ or $f_{\text {ext,Q2, }}$ respectively) is estimated from the measurements of the number fraction of singly and doubly charged particles ( $f_{\mathrm{Q} 1}$ and $f_{\mathrm{Q} 2}$, respectively) determined from either the SMPS (BC2, BC3, and BC3+) or the SP2 (BC4), the per-particle mass of singly and doubly charged particles ( $m_{\mathrm{p}, \mathrm{Q} 1}$ and $m_{\mathrm{p}, \mathrm{Q} 2}$, respectively), with an assumption of spherical particles (i.e., that $m_{\mathrm{p}}=\rho(\pi / 6) d_{\mathrm{p}, \mathrm{VED}}^{3}$ ) and an assumption that the MAC and MEC are size-independent. The resulting expression for $f_{\mathrm{abs}, \mathrm{Q} 2}$ is then

$$
\begin{aligned}
f_{\mathrm{abs}, \mathrm{Q} 2} & =\frac{f_{\mathrm{Q} 2} \cdot m_{\mathrm{p}, \mathrm{Q} 2} \cdot \mathrm{MAC}}{f_{\mathrm{Q} 1} \cdot m_{\mathrm{p}, \mathrm{Q} 1} \cdot \mathrm{MAC}+f_{\mathrm{Q} 2} \cdot m_{\mathrm{p}, \mathrm{Q} 2} \cdot \mathrm{MAC}} \\
& =\frac{f_{\mathrm{Q} 2} \cdot m_{\mathrm{p}, \mathrm{Q} 2}}{f_{\mathrm{Q} 1} \cdot m_{\mathrm{p}, \mathrm{Q} 1}+\left(1-f_{\mathrm{Q} 1}\right) \cdot m_{\mathrm{p}, \mathrm{Q} 2}} \\
& \sim \frac{f_{\mathrm{Q} 2} \cdot d_{\mathrm{p}, \mathrm{VED}, \mathrm{Q} 2}^{3}}{f_{\mathrm{Q} 1} \cdot d_{\mathrm{p}, \mathrm{VED}, \mathrm{Q} 1}^{3}+\left(1-f_{\mathrm{Q} 1}\right) \cdot d_{\mathrm{p}, \mathrm{VED}, \mathrm{Q} 2}^{3}}
\end{aligned}
$$

It is important to note that the final expression is independent of the absolute value of the MAC. A similar procedure was used to correct MEC values. Although the MAC (and MEC) may not be fundamentally size-independent, as assumed, the correction is relatively insensitive to differences in the MAC between sizes. For the size range of interest, there is a relatively constant relationship between the diameters of the singly and doubly charged particles, with $d_{\mathrm{p}, \mathrm{VED}, \mathrm{Q} 2} \sim 1.6 d_{\mathrm{p}, \mathrm{VED}, \mathrm{Q} 1}$ corresponding to $m_{\mathrm{p}, \mathrm{Q} 2} \sim 4 m_{\mathrm{p}, \mathrm{Q} 1}$. Thus,

$f_{\mathrm{abs}, \mathrm{Q} 2} \sim \frac{4\left(1-f_{\mathrm{Q} 1}\right)}{f_{\mathrm{Q} 1}+4\left(1-f_{\mathrm{Q} 1}\right)}$,

and the absorption by Q1 particles only is

$b_{\mathrm{abs}, \mathrm{Q} 1}=b_{\mathrm{abs}, \mathrm{obs}}\left(1-f_{\mathrm{abs}, \mathrm{Q} 2}\right)$.

As an example, if $f_{\mathrm{Q} 1}=0.95$, then $f_{\mathrm{abs}, \mathrm{Q} 2}=0.17$ and the sensitivity of $f_{\text {abs, } 22}$ to uncertainties in $f_{\mathrm{Q} 1}$ is $\delta f_{\text {abs, } 22} \sim 3$. $\delta f_{\mathrm{Q} 1}$, as determined by sensitivity calculations. We estimate that the uncertainty in $f_{\mathrm{Q} 1}$ is 0.01 , which contributes $\sim 3 \%$ to the uncertainty in $b_{\mathrm{abs}, \mathrm{Q} 1}$. (If the MAC were not constant but were instead $20 \%$ larger for Q2s compared to Q1s, then the correction would increase to 0.20 from 0.17 .) For most runs, the Q2 contribution was small, being $5 \%$ or less.

\section{Results and discussion}

Results from the methane diffusion flame and from the two different ethylene premixed flame experiments are presented and discussed separately. For each flame type or configuration, the coated-denuded data for all coating types are considered together.

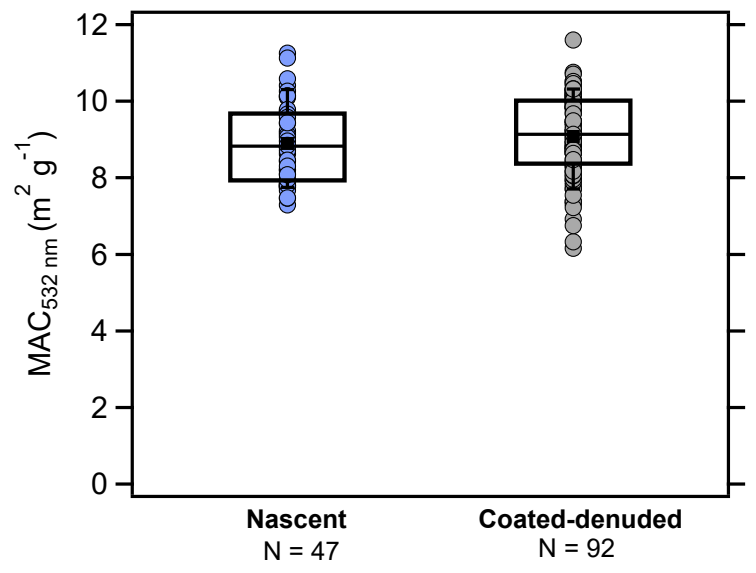

Figure 1. A comparison of methane-diffusion-flame-generated nascent (or nascent-denuded; blue circles) and coated-denuded (gray circles) mass absorption coefficients (MACs) at $\lambda=532 \mathrm{~nm}$ for $x>0.90$ for $\mathrm{BC} 3, \mathrm{BC} 3+$, and $\mathrm{BC} 4$ experiments. Note that conditioning (and therefore the shape) of the soot does not affect the observed MACs. The box and whisker plots show the mean ( $\boldsymbol{\square})$, median (-), lower and upper quartile (boxes), and 9th and 91st percentile (whisker).

\subsection{Soot optical properties from the methane diffusion flame}

\subsubsection{MAC values of nascent and coated-denuded soot}

Average and median MAC values were determined for BC particles from the methane diffusion flame with $x>0.9$ (corresponding to a $d_{\mathrm{p}, \mathrm{VED}}=160 \mathrm{~nm}$ at $\lambda=532 \mathrm{~nm}$; Table S3). (The dimensionless size parameter $x=\pi d_{\mathrm{p}} / \lambda$, where $d_{\mathrm{p}}$ is particle diameter and $\lambda$ is wavelength.) There are no systematic differences in the MAC values between nascent and nascent-denuded $\left(D_{\mathrm{f}, \mathrm{m}}=2.16 \pm 0.1\right)$ and coated-denuded $\left(D_{\mathrm{f}, \mathrm{m}}=2.64 \pm 0.1\right)$ soot at any wavelength for this range of $x$ despite some degree of collapse for the thickly coateddenuded particles (Figs. 1 and S2). The average MAC values for $x>0.9$ were $12.1 \pm 1.4 \mathrm{~m}^{2} \mathrm{~g}^{-1}$ at $405 \mathrm{~nm}, 9.1 \pm$ $1.1 \mathrm{~m}^{2} \mathrm{~g}^{-1}$ at $532 \mathrm{~nm}$, and $7.1 \pm 1.1 \mathrm{~m}^{2} \mathrm{~g}^{-1}$ at $630 \mathrm{~nm}$, where uncertainties are $1 \sigma$ standard deviations of the measurements. For the reverse-coating experiments, which gave broader BC per-particle mass distributions compared to forward-coating distributions, we found no dependence of the derived MAC values on the distribution width. The collapse was presumably due to the effect of evaporation or condensation of the coating material and not due to the denuding process alone (Bhandari et al., 2017). The observed $D_{\mathrm{f}, \mathrm{m}}$ independence of the MAC $(x>0.9)$ is consistent with Radney et al. (2014). This contrasts, however, with modeling studies that use non-Mie-based methods that can account for particle shape effects, which indicate that lacy soot (with a fractal dimension, as opposed to mass mobility exponent, of $\left.D_{\mathrm{f}}=1.8\right)$ is more absorbing than "compact" soot $\left(D_{\mathrm{f}}=2.4\right)$ 
Table 1. Refractive indices for methane diffusion flame soot retrieved via fitting Mie theory and the RDG approximation to the $\sigma_{\text {abs }}$ observations. Nascent and denuded data are combined (see text for details).

\begin{tabular}{|c|c|c|c|c|c|c|c|}
\hline Study & Method & $\lambda(\mathrm{nm})$ & Instrument & $n=m+k_{i}$ & $\begin{array}{l}\text { MAC }_{\text {peak }} \\
\left(\mathrm{m}^{2} \mathrm{~g}^{-1}\right)\end{array}$ & $\begin{array}{c}\mathrm{dp}_{\text {VED,peak }}(\mathrm{nm}) / \\
\text { size param. }\end{array}$ & $\begin{array}{l}\text { Number of } \\
\text { data points }\end{array}$ \\
\hline $\mathrm{BC} 3(+), \mathrm{BC} 4$ & $\mathrm{Mie}^{1}$ & 405 & UCD CRD-PAS & $1.29+1.29 i^{5}$ & $18.72( \pm 6.57)^{5}$ & $61 / 0.47$ & 225 \\
\hline $\mathrm{BC} 3(+), \mathrm{BC} 4$ & $\operatorname{Mie}_{x<0.9}$ & 405 & UCD CRD-PAS & $2.31+1.26 i$ & $12.21( \pm 2.18)$ & $108 / 0.84$ & 40 \\
\hline $\mathrm{BC} 3(+), \mathrm{BC} 4$ & $\mathrm{RDG}^{2,4}$ & 405 & UCD CRD-PAS & $1.80+1.39 i$ & $11.91( \pm 1.97)$ & & 225 \\
\hline $\mathrm{BC} 3(+), \mathrm{BC} 4$ & Mie & 532 & UCD CRD-PAS & $2.24+1.19 i^{5}$ & $9.13( \pm 3.03)^{5}$ & $142 / 0.84$ & 219 \\
\hline $\mathrm{BC} 3(+), \mathrm{BC} 4$ & $\operatorname{Mie}_{x<0.9}$ & 532 & UCD CRD-PAS & $1.96+1.01 i$ & $8.68( \pm 1.08)$ & $137 / 0.82$ & 82 \\
\hline $\mathrm{BC} 3(+), \mathrm{BC} 4$ & RDG & 532 & UCD CRD-PAS & $1.80+1.43 i$ & $8.81( \pm 1.46)$ & & 219 \\
\hline $\mathrm{BC} 3(+), \mathrm{BC} 4$ & Mie & 630 & Aerodyne CAPS & $2.14+0.94 i^{5}$ & $6.93( \pm 0.20)^{5}$ & $181 / 0.90$ & 169 \\
\hline $\mathrm{BC} 3(+), \mathrm{BC} 4$ & $\operatorname{Mie}_{x<0.9}$ & 630 & Aerodyne CAPS & $2.01+0.89 i$ & $6.73( \pm 0.24)$ & $177 / 0.88$ & 134 \\
\hline $\mathrm{BC} 3(+), \mathrm{BC} 4$ & RDG & 630 & Aerodyne CAPS & $1.80+1.13 i$ & $6.51( \pm 1.26)$ & & 169 \\
\hline
\end{tabular}

${ }^{1}$ Uncertainties in the MAC are $1 \sigma$ from the reduced $\chi^{2}$ fit. See Figs. S3 and S4. ${ }^{2}$ The $n$ values from the RDG method are nonunique. Therefore, uncertainty estimates from this work are not available. See text for details. ${ }^{3}$ VED and the size parameter $\left(x=\pi d_{\mathrm{p}} / \lambda\right)$ where the peak MAC occurs. ${ }^{4}$ There are many degenerate RI combinations that give similar quality fit to RDG theory. Thus, a value of 1.80 was chosen for the effective real refractive index. ${ }^{5}$ These values are given for reference purposes only but should not be used due to the inability to fit data well (see text for details).

(Kahnert and Devasthale, 2011; Scarnato et al., 2013). In the calculations, the compact soot particles are less absorbing because the innermost spherules are "shielded" by the outermost spherules. It is possible that the extent of collapse here was insufficient to lead to substantial "shielding" in our experiments. Regardless, given the similarity of the observed nascent and coated-denuded particle cross sections, they have been recombined into a single dataset in what follows.

\subsubsection{RI values calculated from Mie theory and the RDG approximation}

The $\sigma_{\mathrm{abs}}$ have been fit separately using Mie theory and the RDG approximation to determine optimal, theory-specific effective complex RI values. The observations and best fits are shown in Fig. 2 at the three wavelengths $(\lambda=405,532$, and $630 \mathrm{~nm}$ ), and the derived optimal wavelength-, flame-, and theory-specific values are reported in Table 1 . The quality of the best fit obtained is dependent upon both theory and wavelength considered. First, fits performed using Mie theory tend to give reasonably well-defined minima in the calculated $\chi_{\text {red }}^{2}$, indicating that the optimal $m$ and $k$ are unique (Fig. S3). In contrast, fits performed using the RDG approximation do not give a unique set of $m$ and $k$ but instead a band of $[m, k]$ pairs that describe the data equally well (Fig. S4). Since RDG fits are nonunique, optimal $k$ values are reported at all wavelengths for a fixed value of $m=1.80$.

There are additional differences between Mie and RDG beyond the uniqueness of the derived optimal RI. At $\lambda=$ $405 \mathrm{~nm}$, Mie theory provides a poor fit to the $\sigma_{\mathrm{abs}}$ when the fit is performed using data over the entire size range sampled. In particular, at $\lambda=405 \mathrm{~nm}$ the $\sigma_{\text {abs }}$ from Mie theory are overestimated below $d_{\mathrm{p}, \mathrm{VED}} \sim 120 \mathrm{~nm}(x \sim 0.9)$ and underestimated for larger sizes (Fig. 2a). At $\lambda=532 \mathrm{~nm}$, this deviation also occurs at $x \sim 0.9\left(d_{\mathrm{p}, \mathrm{VED}}>160 \mathrm{~nm}\right)$ corresponding to larger size particles. Compared to $405 \mathrm{~nm}$, the overestimate at small $x$ and underestimate at larger $x$ for $532 \mathrm{~nm}$ is smaller. At $\lambda=630 \mathrm{~nm}$, the Mie theory fit compares well with the observations at $x<0.9\left(d_{\mathrm{p}, \mathrm{VED}} \sim 180 \mathrm{~nm}\right)$ and with some deviation observed at larger sizes. When the fits are restricted to $x<0.9$, a reasonable fit using Mie theory is obtained at all wavelengths over this size range, although there is perhaps a small overestimate at the smallest sizes. However, these constrained Mie fits extrapolated to larger sizes $(x>0.9)$ still underestimate the observed absorption. For RDG, generally good fits are obtained at all wavelengths and across all sizes, although the RDG-calculated $\sigma_{\text {abs }}$ tends to overestimate the observation at smaller sizes below $d_{\mathrm{p}, \mathrm{VED}} \sim 100 \mathrm{~nm}$.

It is important to note that the RI values listed in Table 1 are theory- and property-specific. This means that the Miederived RI values are not appropriate for use with the RDG approximation and vice versa. Additionally, they must be used assuming a material density of $1.8 \mathrm{~g} \mathrm{~cm}^{-3}$, since this value was used to convert $m_{\mathrm{p}}$ to $d_{\mathrm{p}, \mathrm{VED}}$ or $N_{\text {spherule. If, for }}$ example, a smaller density were used with these RI values then the particles would have substantially higher MACs. Of note is that both the real and imaginary RIs from Mie theory are larger than RI values that are commonly used in global climate models (Bond et al., 2013), including the RI that is often considered the currently recommended value $(1.95-0.79 i)$ (Bond and Bergstrom, 2006). For reference, using $\mathrm{RI}=1.95-0.79 i$ the MAC at $532 \mathrm{~nm}$ calculated for $\mathrm{BC}$ in the small particle limit (assuming a material density of $1.8 \mathrm{~g} \mathrm{~cm}^{-3}$ ) is only $5.1 \mathrm{~m}^{2} \mathrm{~g}^{-1}$, but peaks at $7.5 \mathrm{~m}^{2} \mathrm{~g}^{-1}$ around $d_{\mathrm{p}, \mathrm{VED}}=150 \mathrm{~nm}$.

\subsubsection{Comparison of measured and calculated MAC values}

Another way to look at the extent to which Mie theory or the RDG approximation can reproduce the observations is to 


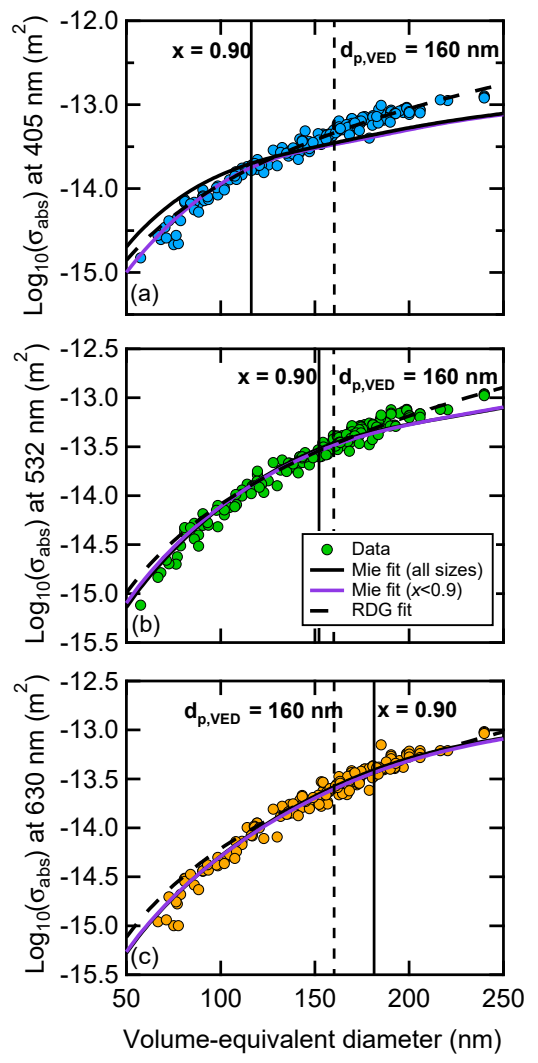

Figure 2. Observed $\sigma_{\mathrm{abs}}$ vs. $d_{\mathrm{p}, \mathrm{VED}}$ methane soot data from BC3, $\mathrm{BC} 3+$, and BC4. Panels (a) and (b) are $\lambda=405$ and $532 \mathrm{~nm}$ data, respectively, from the UCD CRD-PAS, and (c) is $\lambda=630 \mathrm{~nm}$ data from the CAPS PMSSA. The nascent and coated-denuded data have been combined since there is no significant difference in the absorption cross sections and MACs between the two datasets. Note the inability of Mie theory to reproduce the observed $\sigma_{\mathrm{abs}, 405 \mathrm{~nm}}$ for all sizes. Vertical solid lines indicating $x=0.9$, where observations deviate from Mie theory, are provided for reference. In addition, vertical dashed lines indicate $d_{\mathrm{p}, \mathrm{VED}}=160 \mathrm{~nm}$, above which soot maturity is approximately constant.

compare the observed and calculated MAC values as a function of particle size (or $x$ ) rather than the $\sigma_{\mathrm{abs}}$ vs. size relationship (as in Fig. 2). Although the MAC is related directly to the $\sigma_{\mathrm{abs}}$, it is nonetheless useful to consider the MAC values because they vary over a much narrower range than do the $\sigma_{\mathrm{abs}}$. The dependence of the MAC on $d_{\mathrm{p}, \mathrm{VED}}$ and size parameter for both the observations and the models are shown in Fig. 3. The observed MAC values generally increase with $d_{\mathrm{p}, \mathrm{VED}}$ or size parameter at all wavelengths up to around $d_{\mathrm{p}, \mathrm{VED}} \sim 160 \mathrm{~nm}$, above which they plateau and are approximately constant. The ranges (minimum and maximum) of binned observed MACs are provided in Table S4.

The MAC values observed here (Table S3) are substantially larger than the value of $5.7 \pm 0.8 \mathrm{~m}^{2} \mathrm{~g}^{-1}$ at $\lambda=405 \mathrm{~nm}$ reported by Radney et al. (2014), who use a Santoro-type burner (i.e., co-flow diffusion flame). They did not report any notable size dependence for their MAC values. Our MAC values (especially for $x>0.5$ ) compare well with the value of $8.16 \mathrm{~m}^{2} \mathrm{~g}^{-1}$ at $\lambda=532$ reported by You et al. (2016) (extrapolated from $7.89 \pm 0.25 \mathrm{~m}^{2} \mathrm{~g}^{-1}$ at $\lambda=550 \mathrm{~nm}$ ) for soot particles generated from the combustion of organic fuel stock over the $d_{\mathrm{p}, \mathrm{VED}}$ range $\sim 80$ to $\sim 210 \mathrm{~nm}$. They also compare favorably to the range of values 7.2 to $8.5 \mathrm{~m}^{2} \mathrm{~g}^{-1}$ reported for $\lambda=532 \mathrm{~nm}$ for $d_{\mathrm{p}, \mathrm{VED}} \sim 100 \mathrm{~nm}$ observed in Saliba et al. (2016) for particles generated from a cookstove. Some particle size dependence was reported by Khalizov et al. (2009), who used propane with a Santoro-type burner, with reported MACs at $\lambda=532 \mathrm{~nm}$ of $6.7 \pm 0.7 \mathrm{~m}^{2} \mathrm{~g}^{-1}$ for $d_{\mathrm{m}}=155 \mathrm{~nm}$ particles and $8.7 \pm 0.1 \mathrm{~m}^{2} \mathrm{~g}^{-1}$ for $d_{\mathrm{m}}=320 \mathrm{~nm}$ particles. This general behavior was also observed for soot particles generated from a methane diffusion flame in Dastanpour et al. (2017), with MAC values reported at $\lambda=$ $660 \mathrm{~nm}$ of $\sim 5 \mathrm{~m}^{2} \mathrm{~g}^{-1}$ for $d_{\mathrm{p}, \mathrm{VED}}=50 \mathrm{~nm}$ and $\sim 7 \mathrm{~m}^{2} \mathrm{~g}^{-1}$ for $d_{\mathrm{p}, \mathrm{VED}}=100 \mathrm{~nm}$. One key reason that differences may exist between studies is that the BC particles sampled had differing maturity. Soot maturity refers to the extent to which the $\mathrm{BC}$ has a more disordered internal structure with high hydrogen content (low maturity) vs. a more ordered, graphitelike structure with low hydrogen content (high maturity) (Johansson et al., 2017). The absorption cross section for BC likely increases with increasing soot maturity (LópezYglesias et al., 2014).

The observations are compared with the calculated MAC values, based on the fits from Fig. 2. MAC values from the RDG approximation are independent of $x$, as the particle MAC is equal to the MAC of the individual spherules making up the particle. Here, the observed MAC values in the plateau (large $x$ ) regime correspond reasonably well with the MACs as calculated from RDG values when the optimal RI values are used. The constant RDG MAC value at $\lambda=532 \mathrm{~nm}\left(=8.8 \mathrm{~m}^{2} \mathrm{~g}^{-1}\right)$ is slightly larger than the often suggested value for atmospheric $\mathrm{BC}$ by Bond and Bergstrom (2006) of $7.75 \pm 1.2 \mathrm{~m}^{2} \mathrm{~g}^{-1}$ (extrapolated from 7.5 at $\lambda=550 \mathrm{~nm}$ using 1 for the AAE) and is identical to that reported for soot from a Santoro-type diffusion burner operating on propane (Zhang et al., 2008). However, the MACs predicted from RDG overestimate the observed MACs at $x<0.90$, since the RDG fits are weighted by the greater number of data points at $x>0.9$ where MACs are approximately constant.

For Mie theory, calculated MAC values for highly absorbing substances, such as BC, have a characteristic shape where the MAC is constant up to $x \sim 0.2$, increases monotonically by $\sim 40 \%$ until $x \sim 0.9$, and then decreases rapidly towards larger $x$. The Mie theory curves calculated here reproduce the observed values at $x<0.90$ (especially for $\lambda=532$ and $630 \mathrm{~nm}$ ) but substantially underestimated MACs at $x>0.90$. This facilitates an understanding of the Mie model underestimate of $\sigma_{\text {abs }}$ at large $x$ (Fig. 2). Above $x \sim 0.9$ the calculated Mie MAC declines with $x$ for all wavelengths, but the observations indicate that the MAC is constant. Because 
$x$ occurs at smaller $d_{\mathrm{p}, \mathrm{VED}}$ for shorter wavelengths than for longer wavelengths, the model-measurement difference in both $\sigma_{\mathrm{abs}}$ and MAC is more noticeable at $405 \mathrm{~nm}$ than it is at $532 \mathrm{~nm}$, which is more noticeable than at $630 \mathrm{~nm}$. This is a consequence of a greater number of data points at $x>0.9$ at $405 \mathrm{~nm}$, past the peak in the Mie-calculated MAC.

The reasonable correspondence between the observed and Mie-calculated MAC at smaller sizes is, however, somewhat surprising given that Mie assumes spherical particles, yet the particles are not spherical. One potential reason for the observed dependence of the MAC on particle size is that the chemical and optical properties of the particles change with size, and the different chemical composition coincidentally improves agreement with Mie theory. For the diffusion flame, changes in the particle size distribution were induced by changing the amount of dilution nitrogen in the sheath flow. This can influence the maturity of the soot and consequently the soot absorption (López-Yglesias et al., 2014). The observed increase in MAC with $d_{\mathrm{p}, \text { VED }}$ here exhibits some wavelength dependence, which could reflect differences in the sensitivity of the MAC to maturation. The observed differences between the MACs observed at the smallest $x$ and the maximum MAC values were $21 \%, 41 \%$, and $37 \%$ for $\lambda=405 \mathrm{~nm}, \lambda=532 \mathrm{~nm}$, and $\lambda=630 \mathrm{~nm}$, respectively. However, one additional difference between the wavelengths is that at $\lambda=405 \mathrm{~nm}$, there is a small increase in MAC going from $d_{\mathrm{p}, \mathrm{VED}} \sim 60 \mathrm{~nm}\left(x_{405 \mathrm{~nm}}=0.6\right)$ to $\sim 100 \mathrm{~nm}(x=0.9)$ after which the MAC is constant, while at $\lambda=630 \mathrm{~nm}$ there is much more of a continuous increase in the MAC up to larger particle sizes. This could indicate that, at some point, further changes in the soot maturity (composition) have no influence at short wavelengths but do at longer wavelengths. As a complementary explanation, Dastanpour et al. (2017) observed an increase in primary spherule size with overall particle size for methane-diffusion-flame-generated soot. They attribute the increase in MAC with $d_{\mathrm{p}, \mathrm{VED}}$ to changes in the internal structure and/or the degree of graphitization that occur with changes in spherule size.

The observation of constant MAC values for mature soot ( $x>0.9$ or $d_{\mathrm{p}, \mathrm{VED}} \sim 160 \mathrm{~nm}$ at $\lambda=532 \mathrm{~nm}$ ) is an important result in the context of how BC is commonly treated in climate models. Most climate models simulate the optical properties of BC using spherical particle Mie theory. The observations indicate that Mie theory will likely underestimate the absorption by BC for particles with $x>0.9$ because, when the particles are sufficiently absorbing, the attenuation of light by the outer layers of the (spherical) causes the mass in the center of the particle to not interact with the electromagnetic field (Bond and Bergstrom, 2006; Kahnert and Devasthale, 2011). This suggests that the RDG approximation, or even an assumption of a constant MAC, may provide a more accurate representation of $\mathrm{BC}$ absorption than Mie theory in climate models, at least for uncoated BC. This conclusion is independent of soot maturity, as the falloff in the MAC with increasing size for Mie theory occurs for all strongly absorbing particles. Although atmospheric BC particles are predominately generated through the combustion of fossil fuels or through biomass burning (Bond et al., 2013), flamegenerated $\mathrm{BC}$ particles have been shown to be a suitable proxy for atmospheric BC particles, both in terms of chemical bonding and structural properties (Slowik et al., 2007; Hopkins et al., 2007). For example, Hopkins et al. (2007) find that the $\mathrm{sp}^{2}$ content of ethylene and methane flame soot are similar to diesel soot $(63 \%, 60 \%$, and $56 \%$, respectively) and have similar aromatic content. There is also a reasonable similarity between SP-AMS mass spectra of flame soot and soot particles in diesel exhaust or smoke from biomass burning (Onasch et al., 2015a). The absolute values of the derived RI may be different for diesel or biomass BC particles, but it can be reasonably assumed that Mie theory does not reproduce the behavior of atmospheric BC particles.

The discrepancy between Mie theory and the observations is both size and wavelength dependent. Consequently, the extent to which the true absorption by $\mathrm{BC}$ is underestimated by a given atmospheric model due to the inappropriate use of Mie theory will depend importantly on the assumed size distribution, both the position and the width, and the wavelength. Using the effective RI values determined here, we estimate that absorption is underestimated by around $20 \%-$ $40 \%$ when Mie theory is used with reasonable BC size distributions. The underestimate in absorption from the use of Mie theory will be even larger if non-theory-specific (typically lower) imaginary RI values are used, such as that suggested by Hess et al. (1998) or Bond and Bergstrom (2006), as discussed by Stier et al. (2007). Consider that the maximum MAC predicted using the Hess et al. (1998) RI (= $1.75-0.44 i)$ from Mie theory is only $3.8 \mathrm{~m}^{2} \mathrm{~g}^{-1}$.

\subsubsection{MEC and SSA values of nascent and coated-denuded soot}

Measurement of $b_{\text {ext }}$ and the MEC were made in addition to the $b_{\text {abs }}$ and MAC measurements (Fig. 3). Above, the RI fitting was performed using only the absorption measurements, in part because the calculation of extinction using RDG requires additional assumptions regarding the particle shape. Nonetheless, it is informative to compare the $\sigma_{\text {ext }}$ and MEC observations to Mie theory calculations since the overall climate impacts of $\mathrm{BC}$ depend on both absorption and scattering. As with the MAC values, the observed MEC values also increase with $x$ up to 0.90 (or $d_{\mathrm{p}, \mathrm{VED}}$ up to $160 \mathrm{~nm}$ ), after which point they are relatively constant (Fig. 3). The Mie theory MECs calculated using the RIs determined by fitting the absorption measurements (Table 1) agree reasonably well with observations when $x<0.9$ (using the fits that were constrained to this range), but, as with absorption, Mie theory underestimates the MEC above $x=0.9$. For a given particle size, there is somewhat greater scatter in the observed MECs than in the MACs. This is likely a result of the scattering being more sensitive to the shape of the soot particles than is 

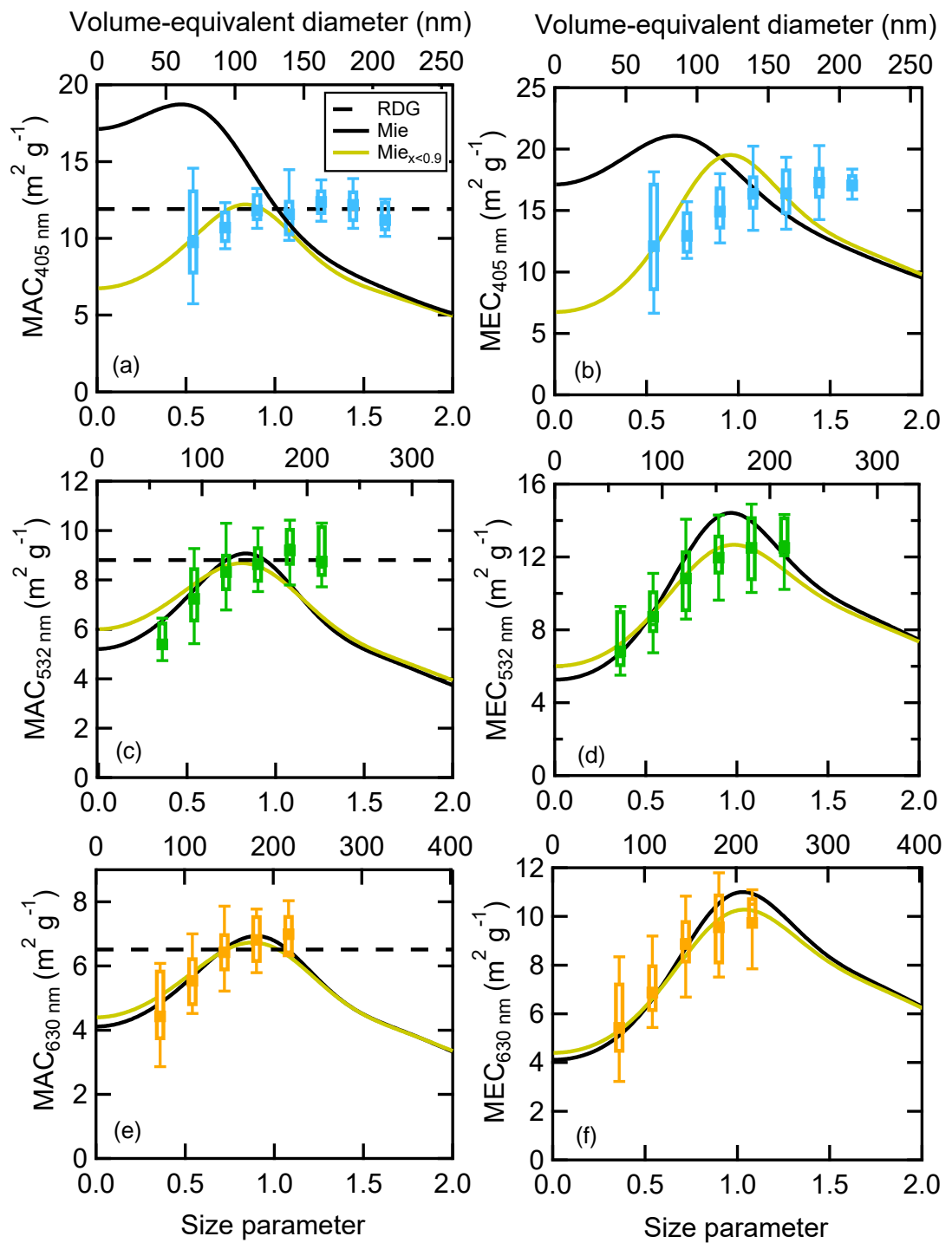

Figure 3. Box plots of MACs and MECs as a function of size parameter, with $\Delta x=0.18$. The volume-equivalent diameters are provided at the top of the plots for reference. Also shown are Mie theory curves for all particles (black solid lines), Mie theory curves for $x<0.90$ (gold line), and RDG curves (dashed line) calculated from the RI values in Table 1. RI fitting was performed using only the absorption measurements. Panels (a) and (b) are $\lambda=405 \mathrm{~nm}$ data from the UCD CRD-PAS, (c) and (d) are $\lambda=532 \mathrm{~nm}$ data from the UCD CRD-PAS, and (e) and (f) are $\lambda=630 \mathrm{~nm}$ data from the CAPS PMSSA. The poor match between the calculated Mie theory curves at $\lambda=405 \mathrm{~nm}$ reflects the difficulties in fitting spherical particle Mie theory to the observed $\sigma_{\mathrm{abs}, 405 \mathrm{~nm}}$ over the entire size range. Although the same particle sizes were sampled over all wavelengths, the size parameters sampled at each wavelength are different. Therefore, there are different numbers of boxes for each wavelength. Note that this figure is directly related to Fig. 2, the difference being that the $y$ axis values in Fig. 2 (cross sections) have been divided by the per-particle mass to give the MAC or MEC. Points in each bin range from $N=10$ at $x_{1.62}$ to $N=81$ at $x_{1.26}$ for $\lambda=405 \mathrm{~nm}, N=5$ at $x_{0.36}$ to $N=82$ at $x_{1.08}$ at $\lambda=532 \mathrm{~nm}$, and $N=8$ at $x_{1.08}$ to $N=67$ at $x_{0.9}$ at $\lambda=630 \mathrm{~nm}$.

absorption and of the nascent and coated-denuded particle results being combined here.

Given this, the dependence of the SSA on particle size is considered separately for the nascent (more lacy) and coated-denuded (more compact) particles. The coateddenuded particle SSAs increase with $d_{\mathrm{p}, \mathrm{VED}}$, most notice- ably for $d_{\mathrm{p}, \mathrm{VED}}>100 \mathrm{~nm}$, up until $d_{\mathrm{p}, \mathrm{VED}} \sim 160 \mathrm{~nm}$. Above this size the SSA values are approximately constant at a value of $\sim 0.30$ (Fig. $4 \mathrm{a}$ ). (Results at $\lambda=532 \mathrm{~nm}$ are shown in Fig. 4a, but there is a strong correlation between SSA at $532 \mathrm{~nm}$ and at 405 or $630 \mathrm{~nm}$; Fig. S5). In contrast, the nascent SSAs increase slightly from $d_{\mathrm{p}, \mathrm{VED}} \sim 50$ to $80 \mathrm{~nm}$ 
but above $80 \mathrm{~nm}$ are approximately constant at $\sim 0.20$. This demonstrates that particle collapse leads to an increase in the SSA for BC, consistent with Radney et al. (2014). This behavior is also consistent with modeling studies, which have predicted that compact agglomerates exhibit higher SSA values than lacy agglomerates, with an absolute increase of $\triangle \mathrm{SSA} \sim 0.1$ (Scarnato et al., 2013) or by a factor of 1.22.2, depending on the extent of compaction (China et al., $2015 \mathrm{a}, \mathrm{b})$. The increase upon collapse is attributed to the stronger scattering and electromagnetic coupling between spherules in compact aggregates. Here, the difference between the SSA for nascent and coated-denuded soot increases somewhat with particle size, which may result from changes in soot maturity with size. The SSAs from this study compare reasonably well to values reported previously at visible wavelengths. For example, Saliba et al. (2016) report $\mathrm{SSA}=0.16$ to 0.26 for nascent soot emitted from a cookstove; Schnaiter et al. $(2003,2006)$ report $\mathrm{SSA}=0.2$ to 0.3 for soot from a propane diffusion flame, $\mathrm{SSA}=0.18$ to 0.25 for kerosene-derived soot, and SSA $=0.1$ to 0.25 for methane diffusion flame soot; and Sharma et al. (2013) report $\mathrm{SSA}=0.18$ to 0.25 for soot generated from a kerosene lamp. However, the values reported here are much smaller than the value of 0.5 reported in Radney et al. (2014). The Mietheory-calculated SSA values are similar to observations, although they show a somewhat stronger increase with size and seem to plateau at larger SSA values at large sizes compared to observations.

\subsubsection{AAE of nascent and coated-denuded soot}

The wavelength dependence of absorption has been considered by calculating the AAE using the measurements at $\lambda=$ 405 and $532 \mathrm{~nm}$ (Fig. 4b). The nascent AAEs at larger particle sizes are slightly larger than the coated-denuded AAEs, suggesting that particle collapse leads to a slight decrease in the wavelength dependence of absorption. The average AAE was $1.38 \pm 0.36(N=85)$ and $1.10 \pm 0.37(N=135)$ for nascent and coated-denuded particles, respectively. There is some indication that AAE decreases with particle size. This may again be the result of the soot maturity increasing (and the composition changing) with size. The AAE values from Mie theory, based on the best-fit RI values determined above, exhibit an increase to $x \sim 0.5$ where they peak and then decrease sharply. This predicted decrease is inconsistent with the observations. The AAEs calculated using the RDG approximation from the best-fit RI values are constant.

$\mathrm{BC}$ is commonly assumed to have an $\mathrm{AAE}=1$ (Bergstrom, 1973). The measurements here are consistent with this expectation for the collapsed (coated-denuded) particles, but the nascent particles give an AAE that is somewhat larger than 1. The observed AAE values are similar to results from previous studies examining either freshly emitted soot particles or soot particles containing very little organic ma-
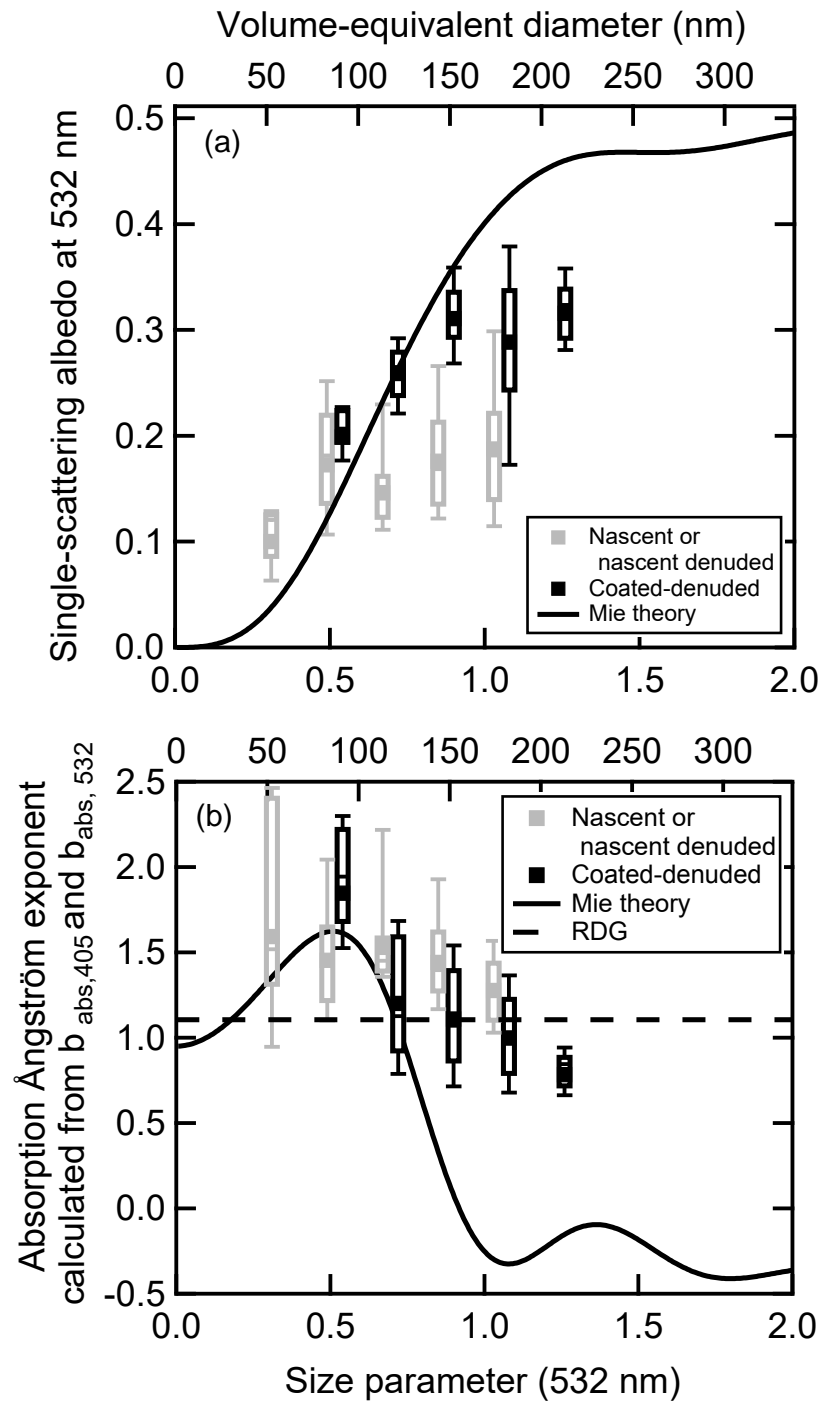

Figure 4. Box and whisker plots of $\lambda=532 \mathrm{~nm}$ (a) single-scattering albedo (SSA) and (b) absorption Ångström exponent (AAE) as a function of volume-equivalent diameter produced from the methane diffusion flame. The black points are coated-denuded data (coating material is evaporated following coating with DOS or sulfuric acid) and are potentially collapsed due to coating, and the gray points are nascent or nascent-denuded data. The black lines are the SSA or AAE predicted by spherical particle Mie theory, and the dashed black line in (b) is AAE predicted from the RDG approximation using the effective refractive indices listed in Table 1 . The nascent or nascent-denuded boxes (black) are shifted by $X=0.05$. Points in each bin range from $N=6$ at $x_{0.36}$ to $N=26$ at $x_{1.08}$ for nascent (or nascent-denuded) and $N=5$ at $x_{0.54}$ to $N=9$ at $x_{1.26}$ for coated-denuded points. 
terial (Schnaiter et al., 2003, 2006; Kirchstetter et al., 2004; Bergstrom et al., 2002; You et al., 2016; Sharma et al., 2013).

\subsection{Optical properties of $\mathrm{BC}$ from the ethylene flat-burner flames}

\subsubsection{Results from BC2: sampling high above the burner surface}

During $\mathrm{BC} 2$, the ethylene flame was sampled at a height of $\sim 20.3 \mathrm{~cm}$ above the surface. At this height, the particles were likely reasonably mature, at least relative to sampling that was performed further into the flame, as was done in $\mathrm{BC} 3+$. Particle optical properties were quantified at $\lambda=$ 405,532 , and $781 \mathrm{~nm}$, with two independent measurements at $532 \mathrm{~nm}$ considered (NOAA and PASS-3). As with the methane diffusion flame, the data were fit using Mie theory and the RDG approximation to determine optimal, theoryspecific, wavelength-dependent RI values (Table 2). The soot particles from this flame had, overall, a greater amount of intrinsic organic carbon associated with them compared to the particles from the methane diffusion flame. As such, denuding even of the nascent particles led to changes in the optical properties and particle masses. Thus, the nascent and denuded particles are considered separately, and we focus on the denuded particles. The range of particle sizes considered was also overall smaller than that for the methane diffusion flame.

The retrieval of effective refractive indices for this flame using Mie theory resulted in a good fit to $\sigma_{\mathrm{abs}} \mathrm{vs.} d_{\mathrm{p}, \mathrm{VED}}$ for all $\lambda$ and $d_{\mathrm{p}, \text { VED }}$ (Fig. 5a, d, g, and j, and Figs. S6-S7). This difference from the methane diffusion flame is in large part due to the more restricted size range encountered here, with $\mathrm{BC}$ particles only up to $d_{\mathrm{p}, \mathrm{VED}}=160 \mathrm{~nm}$ used. The RDG approximation yielded a reasonably good fit across all particle sizes for the ethylene particles, although with some overestimation at smaller sizes. The MAC values tended to increase with particle size or size parameter, most obviously at $532 \mathrm{~nm}$ where the most data points are available (Fig. 5b, $\mathrm{e}, \mathrm{h}$, and $\mathrm{k}$ ). The range of binned MACs shown in Fig. 5 is listed in Table S4. The MAC values determined using the two PAS instruments at $532 \mathrm{~nm}$ differ somewhat, with the NOAA PAS MACs slightly larger than PASS-3 MACs, although the differences are within the measurement uncertainties. Most likely, this instrument difference stems from differences in calibration methods.

The observed MAC values tend to be larger for the denuded particles than for the nascent particles, most likely due to less-absorbing organics present in nascent soot that contribute $\sim 25 \%$ of the particle mass (Cross et al., 2010). The MAC values at $\lambda=405$ and $532 \mathrm{~nm}$ for the denuded $\mathrm{BC} 2$ ethylene flame soot are comparable, within uncertainty, to the MAC values for the methane diffusion flame soot for the particles with $d_{\mathrm{p}, \mathrm{VED}} \sim 150 \mathrm{~nm}$. This indicates that the BC from these two flames is similarly absorbing in nature.
The impact of particle morphology on the SSA and AAE is considered by comparing the results for nascent-denuded particles with coated-denuded particles (Fig. 6). Nascent particles are excluded because the presence of intrinsic organics can increase AAE if the organic material contains brown carbon and can increase the SSA independent of the underlying BC morphology. The $D_{\mathrm{f}, \mathrm{m}}$ values were $2.12 \pm$ $0.06,2.49 \pm 0.07$, and $2.17 \pm 0.06$ for nascent-denuded, sulfuric acid coated-denuded, and DOS coated-denuded soot, respectively (Cross et al., 2010). The nascent-denuded and DOS coated-denuded particles have SSA values close to 0 , whereas the sulfuric acid coated-denuded particles have SSA values closer to 0.15 at $x>0.5$, consistent with particle collapse leading to an increase in SSA (Fig. 6a). The SSA values for the nascent-denuded particles from this flame are smaller than the SSA values for the nascent particles from the methane diffusion flame. The reason for this is not clear but is likely related to differences in the particle shapes and/or the sizes of the spherules; the $D_{\mathrm{f}, \mathrm{m}}$ for the nascent-denuded particles here $\left(D_{\mathrm{f}, \mathrm{m}}=2.12\right)$ is slightly smaller than for the particles from the methane diffusion flame $\left(D_{\mathrm{f}, \mathrm{m}}=2.28\right)$ (Fig. S8). The sulfuric acid coated-denuded particle SSA values from the $\mathrm{BC} 2$ ethylene flame are also lower than the methane diffusion flame coated-denuded SSA values for a given size (Fig. 6a), despite having similar $D_{\mathrm{f}, \mathrm{m}}$ values.

The AAE values (using the $\lambda=405$ and $532 \mathrm{~nm}$ pair) for nascent-denuded and coated-denuded particles are generally similar when compared over the same size range (Fig. 6b). However, the sulfuric acid coated-denuded particle AAE values may be slightly smaller than for the nascent-denuded or DOS coated-denuded particles; all are close to unity at $x \sim$ 0.8 . This indicates that changes in morphology do not lead to substantial changes in AAE. The AAEs for the coateddenuded particles decrease strongly with $d_{\mathrm{p}, \mathrm{VED}}$, with the mean AAE $\sim 1.6$ for the smallest particles $(x=0.5)$ and an AAE mean of $\sim 0.5$ for the largest particles $(x=0.9)$. Values below 1 contrast with the methane data but have been observed in a few previous studies (Clarke et al., 2007; Hadley et al., 2008; Lack et al., 2008). While such a decrease with size is consistent with Mie theory predictions, given the MAC results, it seems more likely that the size dependence of the AAE is related to changes in the soot maturity with particle size. To the extent that the larger particles, which tend to have larger MAC values, are reflective of more mature soot, this suggests that mature soot from this flame type has an $\mathrm{AAE}<1$.

\subsubsection{Results from BC3+: sampling near the burner surface}

During $\mathrm{BC} 3+$, the particles were sampled at variable heights above the burner surface to select for particles in different size ranges, but most often they were sampled from relatively close to the burner surface $(5.1 \mathrm{~cm})$ compared to $\mathrm{BC} 2$ sampling conditions $(20.3 \mathrm{~cm})$. It is likely that these differ- 

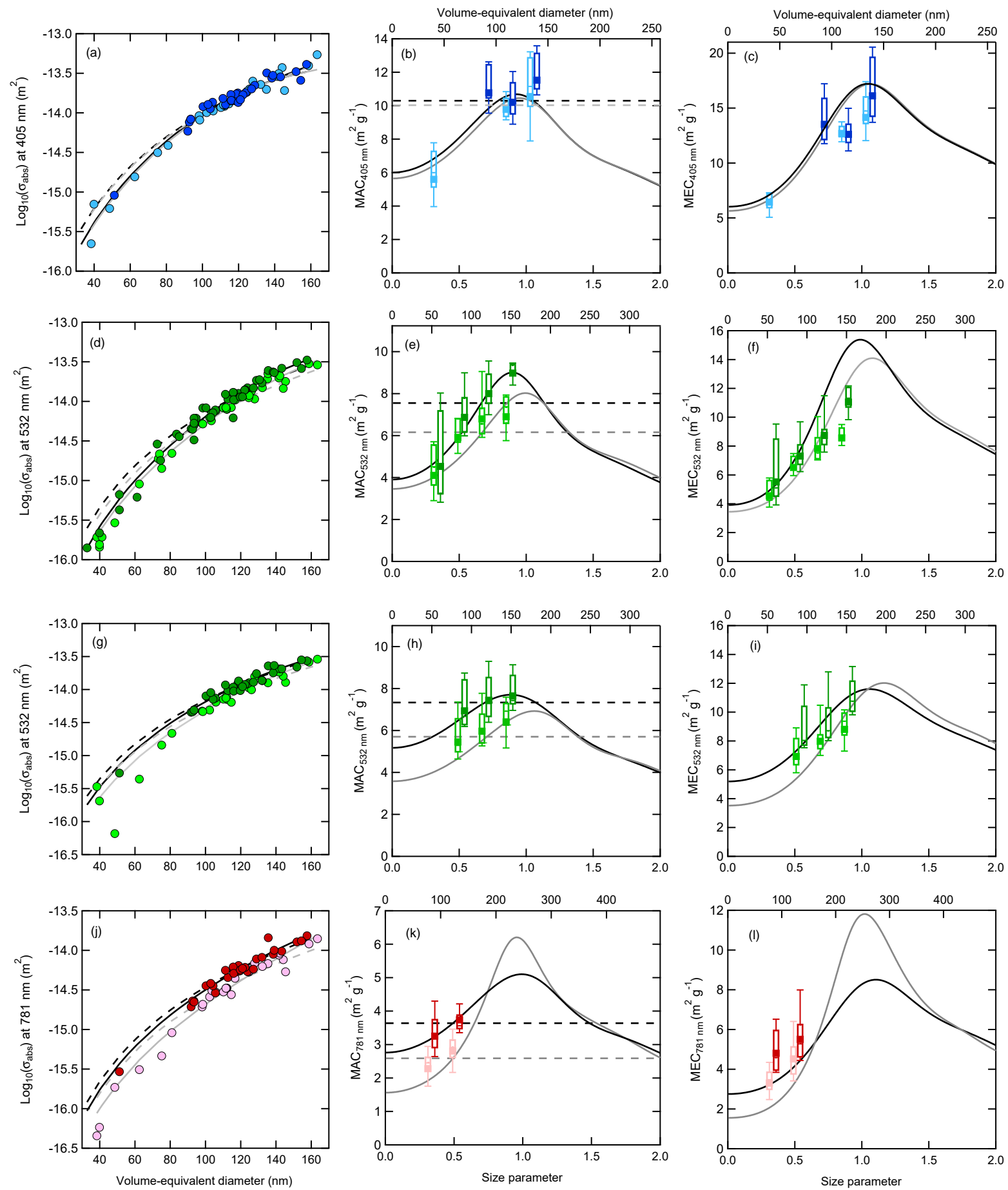

Figure 5. Measured absorption cross sections vs. volume-equivalent diameter (panels in the first column) and mass absorption and extinction coefficients (MACs and MECs; panels in the second and third column, respectively) for ethylene soot sampled $20.3 \mathrm{~cm}$ from burner surface of the McKenna flame as a function of size parameter $\left(x=\pi d_{\mathrm{p}} / \lambda\right)$ (bottom axes) and volume-equivalent diameter (top axes). for BC2. Panels (a-c) show PASS-3 data at $\lambda=405 \mathrm{~nm},(\mathbf{d}-\mathbf{f})$ show NOAA PAS data at $\lambda=532 \mathrm{~nm},(\mathbf{g}-\mathbf{i})$ show PASS- 3 data at $\lambda=532 \mathrm{~nm}$, and (j-l) show PASS-3 data at $\lambda=781 \mathrm{~nm}$. The dashed black and gray lines are the RDG fits to denuded and nascent data, respectively, and the solid black and gray lines are Mie fits to denuded and nascent data, respectively. 
Table 2. Theory-specific effective refractive indices for ethylene premixed flame soot from BC2 and BC3+ retrieved via fitting Mie theory and the RDG approximation to the $\sigma_{\mathrm{abs}}$ observations. Nascent and denuded experiments are considered separately.

\begin{tabular}{|c|c|c|c|c|c|c|c|c|}
\hline Study ${ }^{5}$ & Soot type & Method & $\lambda(\mathrm{nm})$ & Instrument & $n=m+k_{i}$ & $\begin{array}{l}\mathrm{MAC}_{\text {peak }} \\
\left(\mathrm{m}^{2} \mathrm{~g}^{-1}\right)\end{array}$ & $\begin{array}{r}\mathrm{dp}_{\text {VED,peak }}(\mathrm{nm}) / \\
\text { size param. }\end{array}$ & $\begin{array}{l}\text { Number of } \\
\text { data points }\end{array}$ \\
\hline $\mathrm{BC} 2$ & Nascent & $\mathrm{Mie}^{1}$ & 405 & PASS-3 & $2.21+0.86 i$ & $10.45( \pm 2.06)$ & $123 / 0.95$ & 36 \\
\hline $\mathrm{BC} 2$ & Denuded & Mie & 405 & PASS-3 & $2.19+0.91 i$ & $10.68( \pm 1.97)$ & $119 / 0.92$ & 30 \\
\hline $\mathrm{BC} 2$ & Nascent & $\mathrm{RDG}^{2,4}$ & 405 & PASS-3 & $1.80+1.13 i$ & $10.06( \pm 2.22)$ & & 36 \\
\hline $\mathrm{BC} 2$ & Denuded & RDG & 405 & PASS-3 & $1.80+1.18 i$ & $10.32( \pm 2.56)$ & & 30 \\
\hline $\mathrm{BC} 2$ & Nascent & Mie & 532 & PASS-3 & $2.13+0.64 i$ & $6.92( \pm 0.78)$ & $178 / 1.07$ & 36 \\
\hline $\mathrm{BC} 2$ & Nascent & Mie & 532 & NOAA CRD-PAS & $2.39+0.79 i$ & $8.02( \pm 0.13)$ & $169 / 0.99$ & 43 \\
\hline $\mathrm{BC} 2$ & Denuded & Mie & 532 & PASS3 & $1.96+0.83 i$ & $7.70( \pm 0.90)$ & $150 / 0.89$ & 31 \\
\hline $\mathrm{BC} 2$ & Denuded & Mie & 532 & NOAA CRD-PAS & $2.56+1.11 i$ & $9.00( \pm 0.80)$ & $152 / 0.90$ & 46 \\
\hline $\mathrm{BC} 2$ & Nascent & RDG & 532 & PASS-3 & $1.80+0.78 i$ & $6.92( \pm 0.43)$ & & 36 \\
\hline $\mathrm{BC} 2$ & Nascent & RDG & 532 & NOAA CRD-PAS & $1.80+0.85 i$ & $6.16( \pm 1.75)$ & & 43 \\
\hline $\mathrm{BC} 2$ & Denuded & RDG & 532 & PASS-3 & $1.80+1.08 i$ & $7.35( \pm 1.69)$ & & 31 \\
\hline $\mathrm{BC} 2$ & Denuded & RDG & 532 & CRD-PAS & $1.80+1.13 i$ & $7.55( \pm 0.68)$ & & 46 \\
\hline $\mathrm{BC} 2$ & Nascent & Mie & 781 & PASS-3 & $2.16+0.76 i$ & $5.10( \pm 0.40)$ & $250 / 0.96$ & 31 \\
\hline $\mathrm{BC} 2$ & Denuded & Mie & 781 & PASS-3 & $2.84+0.74 i$ & $6.20( \pm 0.20)$ & $239 / 0.95$ & 36 \\
\hline $\mathrm{BC} 2$ & Nascent & RDG & 781 & PASS-3 & $1.80+0.50 i$ & $2.59( \pm 0.33)$ & & 36 \\
\hline $\mathrm{BC} 2$ & Denuded & RDG & 781 & PASS-3 & $1.80+0.73 i$ & $3.64( \pm 0.81)$ & & 31 \\
\hline $\mathrm{BC} 3+$ & Denuded & Mie & 405 & UCD CRD-PAS & $2.11+1.03 i$ & $11.09( \pm 2.82)$ & $110 / 0.85$ & 27 \\
\hline $\mathrm{BC} 3+$ & Denuded & RDG & 405 & UCD CRD-PAS & $1.80+2.05 i$ & $10.78( \pm 3.11)$ & & 27 \\
\hline $\mathrm{BC} 3+$ & Denuded & Mie & 532 & UCD CRD-PAS & $1.46+0.54 i$ & $6.03( \pm 1.12)$ & $118 / 0.70$ & 22 \\
\hline $\mathrm{BC} 3+$ & Denuded & RDG & 532 & UCD CRD-PAS & $1.80+0.76 i$ & $5.61( \pm 0.46)$ & & 22 \\
\hline $\mathrm{BC} 3+$ & Denuded & Mie & 630 & CAPS PMSSA & $1.78+0.45 i$ & $3.93( \pm 0.90)$ & $188 / 0.93$ & 22 \\
\hline $\mathrm{BC} 3+$ & Denuded & RDG & 630 & CAPS PMSSA & $1.80+0.55 i$ & $3.51( \pm 1.55)$ & & 22 \\
\hline
\end{tabular}

${ }^{1}$ Uncertainties in MACs are $1 \sigma$ from the least $\chi^{2}$ fit. See Figs. S7 and S8. ${ }^{2}$ The $n$ values from the RDG method are nonunique. Therefore, uncertainty estimates from this work are not available. See text for details. ${ }^{3}$ VED and the size parameter $\left(x=\pi d_{\mathrm{p}} / \lambda\right)$ where the peak MAC occurs. ${ }^{4}$ There are many degenerate RI combinations that give similar quality fit to RDG theory. Thus, a value of 1.80 was chosen for the effective real refractive index. ${ }^{5}$ In BC2 the ethylene flat-burner flame was sampled $20.3 \mathrm{~cm}$ between the burner surface and the sampling inlet, and during BC 3 the flame was sampled ca. $5 \mathrm{~cm}$ between the burner surface and the sampling inlet.

ent sampling conditions gave rise to particles with different chemical properties. Multiple studies have shown changes in soot maturity and soot optical properties as a function of sampling height in ethylene premixed flames, though at a distance significantly closer to the flame front than sampled here (Olofsson et al., 2015; Migliorini et al., 2011). The particles during $\mathrm{BC} 3+$ had very little, if any, intrinsic organic carbon, unlike the $\mathrm{BC} 2$ particles that were $\sim 25 \%$ organic by mass. However, the small organic content for $\mathrm{BC} 3+$ was likely a consequence of the use of a hot sampling line prior to dilution. Consequently, the optical properties of both nascent and denuded ethylene soot particles from $\mathrm{BC} 3+$ (sampled close to the burner) differ substantially from the BC2 particles (sampled well above the burner). Average MAC values over various size ranges are listed in Table S5. In general, the MACs for $\mathrm{BC} 3+$ ethylene particles are similar to $\mathrm{BC} 2$ particles at $\lambda=405 \mathrm{~nm}$, whereas the $\lambda=532 \mathrm{~nm}$ MAC for BC3+ particles are smaller than those for BC2 particles. (Measurements at $\lambda=30 \mathrm{~nm}$ were not made during $\mathrm{BC} 2$, nor were measurements at $781 \mathrm{~nm}$ made during $\mathrm{BC} 3+$.) At $d_{\mathrm{p}, \mathrm{VED}}>70 \mathrm{~nm}$, the $\lambda=405 \mathrm{~nm}$ MAC values were approximately constant with increasing $d_{\mathrm{p}, \mathrm{VED}}$ (Fig. S9). The behavior is consistent with methane diffusion flame observations, but the constant MAC seems to occur at a lower $d_{\mathrm{p} \text {,VED }}$. The number of data points available for the $\mathrm{BC} 3+$ ethylene particles is limited, making conclusions regarding the size dependence of properties somewhat tenuous. The AAE for $\mathrm{BC} 3+$ ethylene particles are reasonably independent of particle size (Fig. S10). The average value of $\mathrm{AAE}_{405 \mathrm{~nm}-532 \mathrm{~nm}}=2.01 \pm 0.21$ for $x>0.5$, which is higher than observed for the methane diffusion flame for this range of $x(=1.18 \pm 0.35)$. These observations indicate that differences in sampling and soot maturity result in different optical properties. Previous studies have observed differences in optical properties, chemical composition, and primary spherule size for different flame sampling heights (Bladh et al., 2011; Olofsson et al., 2015; Migliorini et al., 2011). Absorption by less mature soot appears to decrease more rapidly with wavelength than for more mature soot, such that the MAC values in the mid-visible (e.g., $\lambda=532$ and $630 \mathrm{~nm}$ ) are lower for less mature soot. These wavelength-dependent optical results appear to match trends observed previously using active remote-sensing techniques to characterize particles within flames (Olofsson et al., 2015; Migliorini et al., 2011). The extent to which this conclusion can be generalized will require further investigation. 


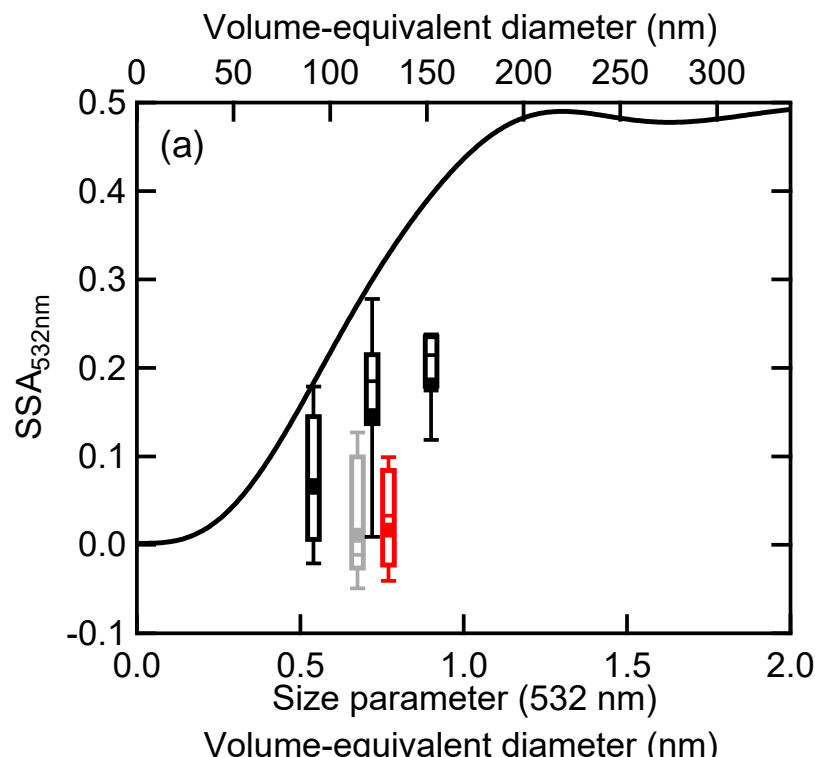

\section{Conclusion}

Light absorption and extinction cross sections were measured for nascent, denuded, and coated-denuded soot particles that were produced from two different flame types that operated on different fuels (methane or ethylene). These measurements were used in conjunction with particle mass and size measurements to determine various intensive optical properties (e.g., MAC, SSA, and AAE) for uncoated BC particles in the size range $50 \mathrm{~nm}<d_{\mathrm{p}, \mathrm{VED}}<210 \mathrm{~nm}$ (corresponding to $0.1 \mathrm{fg}<m_{\mathrm{p}}<5 \mathrm{fg}$ ). The optical properties varied somewhat with particle size, most likely due to changes in the chemical nature (i.e., maturity) of the $\mathrm{BC}$ that results from variations in the combustion and sampling conditions. However, for larger, mature particles, corresponding to those with $d_{\mathrm{p}, \mathrm{VED}}>\sim 160 \mathrm{~nm}$, the observed intensive properties were generally size-independent. The observed MAC values for BC, measured over multiple studies, are independent of particle collapse and thus provide evidence that absorption by soot of a given maturity level is dictated primarily by the individual spherules and is thus largely size- and shapeindependent. The observed MAC values are also larger than the recommended value of Bond and Bergstrom (2006), i.e., $8.6 \mathrm{~m}^{2} \mathrm{~g}^{-1}$ vs. $7.75 \mathrm{~m}^{2} \mathrm{~g}^{-1}$ at $532 \mathrm{~nm}$.

The observations serve as the basis for the determination of wavelength- and theory-specific effective complex refractive indices, using both Mie theory and the RDG approximation. With Mie theory, good fits were only obtained for size parameters smaller than $\sim 0.90$ (corresponding to $d_{\mathrm{p}, \mathrm{VED}} \sim 160 \mathrm{~nm}$ for $\lambda=532 \mathrm{~nm}$ ). Above this size, Mie theory predicts a sharp decrease in the MAC while the observed MAC are constant. Thus, Mie theory systematically underpredicts the observed absorption for $x>0.9$, and a good fit is not possible. This is because with Mie theory when the particles are sufficiently absorbing and large, light is attenuated by the outer layers of the (spherical) particle such that the mass in the center of the particle does not interact efficiently with the electromagnetic field (Bond and Bergstrom, 2006; Kahnert and Devasthale, 2011).

Our analysis has important implications for the calculation of absorption in atmospheric models. Atmospheric models that use Mie theory, which is the majority, likely underestimate the actual absorption by uncoated $\mathrm{BC}$ whether or not theory-specific RI values are used; the magnitude of the underestimation will depend on the assumed $\mathrm{BC}$ size distributions, increasing with increasing $d_{\mathrm{p}, \mathrm{VED}}$ and size distribution width. This may be especially important to consider for the simulation of absorption by BC particles from biomass burning, which are larger than those from urban sources (Schwarz et al., 2008). The underestimate of absorption by Mie theory will likely be even larger if non-theory-specific RI values that inherently underestimate MAC values are used, which includes some of the more commonly used RI values.

Overall, our results demonstrate that either an assumption of a constant MAC or the use of the RDG approximation 
with theory-specific RI values (which are equivalent) in atmospheric models are likely to provide for a more accurate representation of absolute absorption by uncoated $\mathrm{BC}$ than does Mie theory. Further work will be necessary to understand how these results for uncoated BC will impact calculations of absorption by coated $\mathrm{BC}$, for which absorption can be enhanced. However, our results suggest that the absolute absorption by coated particles will be similarly underestimated if core-shell Mie theory is used, regardless of the accuracy of the absorption enhancement calculation.

Data availability. The data associated with this paper are archived at the UC Davis DASH data repository and are available for download from https://doi.org/10.25338/B8JP4V (Forestieri and Cappa, 2018).

Supplement. The supplement related to this article is available online at: https://doi.org/10.5194/acp-18-12141-2018-supplement.

Author contributions. SDF and CDC led the analysis. TBO and PD conceived the overall project, with contributions from CDC, ATL, and others on experimental design. All coauthors contributed to data collection and/or processing. SDF and CDC prepared the paper with particular input from TBO and contributions from all coauthors.

Competing interests. The authors declare that they have no conflict of interest.

Acknowledgements. The BC2 study was supported by the US Department of Energy (DOE) grant no. DE-FG02-05ER63995 and the Atmospheric Chemistry Program of the National Science Foundation grants no. ATM-0525355. The BC3 and BC3+ studies were supported by the DOE ASR program grant DE-SC0006980, the EPA STAR Program grant R835033, and the NSF grant ATM-0854916. The BC4 study was supported by DOE grant DESC0011935 and the NSF grants AGS-1244918 (Boston College) and AGS-1244999 (Aerodyne), and the participation of the SP2 was made possible by DOE. LANL thanks the US Department of Energy's Atmospheric System Research, an Office of Science, Office of Biological and Environmental Research program for funding.

Edited by: Delphine Farmer

Reviewed by: three anonymous referees

\section{References}

Bergstrom, R. W.: Extinction and absorption coefficients of the atmospheric aerosol as a function of particle size, Contrib. Atmos. Phys., 46, 223-234, 1973.

Bergstrom, R. W., Russell, P. B., and Hignett, P.: Wavelength dependence of the absorption of black carbon particles: Predictions and results from the TARFOX experiment and implications for the aerosol single scattering albedo, J. Atmos. Sci., 59, 567-577, https://doi.org/10.1175/15200469(2002)059<0567:wdotao>2.0.co;2, 2002.

Bhandari, J., China, S., Onasch, T., Wolff, L., Lambe, A., Davidovits, P., Cross, E., Ahern, A., Olfert, J., Dubey, M., and Mazzoleni, C.: Effect of Thermodenuding on the Structure of Nascent Flame Soot Aggregates, Atmosphere, 8, 166, https://doi.org/10.3390/atmos8090166, 2017.

Bladh, H., Johnsson, J., Olofsson, N. E., Bohlin, A., and Bengtsson, P. E.: Optical soot characterization using two-color laserinduced incandescence (2C-LII) in the soot growth region of a premixed flat flame, Proc. Combust. Inst., 33, 641-648, https://doi.org/10.1016/j.proci.2010.06.166, 2011.

Bohren, C. F. and Huffman, D. R.: Absorption and scattering of light by small particles, Wiley, New York, 1983.

Bond, T. C. and Bergstrom, R. W.: Light Absorption by Carbonaceous Particles: An Investigative Review, Aerosol Sci. Tech., 40, 27-67, https://doi.org/10.1080/02786820500421521, 2006.

Bond, T. C., Doherty, S. J., Fahey, D. W., Forster, P. M., Berntsen, T., DeAngelo, B. J., Flanner, M. G., Ghan, S., Kärcher, B., Koch, D., Kinne, S., Kondo, Y., Quinn, P. K., Sarofim, M. C., Schultz, M. G., Schulz, M., Venkataraman, C., Zhang, H., Zhang, S., Bellouin, N., Guttikunda, S. K., Hopke, P. K., Jacobson, M. Z., Kaiser, J. W., Klimont, Z., Lohmann, U., Schwarz, J. P., Shindell, D., Storelvmo, T., Warren, S. G., and Zender, C. S.: Bounding the role of black carbon in the climate system: A scientific assessment, J. Geophys. Res.-Atmos., 118, 5380-5552, https://doi.org/10.1002/jgrd.50171, 2013.

Boucher, O., Randall, D., Artaxo, P., Bretherton, C., Feingold, G., Forster, P., Kerminen, V.-M., Kondo, Y., Liao, H., Lohmann, U., Rasch, P., Satheesh, S. K., Sherwood, S., Stevens, B., and Zhang, X. Y.: Clouds and Aerosols, in: Climate Change 2013: The Physical Science Basis, Contribution of Working Group I to the Fifth Assessment Report of the Intergovernmental Panel on Climate Change, edited by: Stocker, T. F., Qin, D., Plattner, G.-K., Tignor, M., Allen, S. K., Boschung, J., Nauels, A., Xia, Y., Bex, V., and Midgley, P. M., Cambridge University Press, Cambridge, UK, New York, NY, USA, 571-658, 2013.

Canagaratna, M. R., Jayne, J. T., Jimenez, J. L., Allan, J. D., Alfarra, M. R., Zhang, Q., Onasch, T. B., Drewnick, F., Coe, H., Middlebrook, A., Delia, A., Williams, L. R., Trimborn, A. M., Northway, M. J., DeCarlo, P. F., Kolb, C. E., Davidovits, P., and Worsnop, D. R.: Chemical and microphysical characterization of ambient aerosols with the aerodyne aerosol mass spectrometer, Mass Spectrom. Rev., 26, 185-222, https://doi.org/10.1002/mas.20115, 2007.

Cappa, C. D. and Wilson, K. R.: Evolution of organic aerosol mass spectra upon heating: implications for OA phase and partitioning behavior, Atmos. Chem. Phys., 11, 1895-1911, https://doi.org/10.5194/acp-11-1895-2011, 2011.

Cappa, C. D., Onasch, T. B., Massoli, P., Worsnop, D. R., Bates, T. S., Cross, E. S., Davidovits, P., Hakala, J., Hayden, K. L., 
Jobson, B. T., Kolesar, K. R., Lack, D. A., Lerner, B. M., Li, S.-M., Mellon, D., Nuaaman, I., Olfert, J. S., Petäjä, T., Quinn, P. K., Song, C., Subramanian, R., Williams, E. J., and Zaveri, R. A.: Radiative Absorption Enhancements Due to the Mixing State of Atmospheric Black Carbon, Science, 337, 1078-1081, https://doi.org/10.1126/science.1223447, 2012.

China, S., Kulkarni, G., Scarnato, B. V., Sharma, N., Pekour, M., Shilling, J. E., Wilson, J., Zelenyuk, A., Chand, D., and Liu, S.: Morphology of diesel soot residuals from supercooled water droplets and ice crystals: implications for optical properties, Environ. Res. Lett., 10, 114010, https://doi.org/10.1088/17489326/10/11/114010, 2015a.

China, S., Scarnato, B., Owen, R. C., Zhang, B., Ampadu, M. T., Kumar, S., Dzepina, K., Dziobak, M. P., Fialho, P., Perlinger, J. A., Hueber, J., Helmig, D., Mazzoleni, L. R., and Mazzoleni, C.: Morphology and mixing state of aged soot particles at a remote marine free troposphere site: Implications for optical properties, Geophys. Res. Lett., 42, 1243-1250, https://doi.org/10.1002/2014GL062404, 2015b.

Chow, J. C., Watson, J. G., Chen, L.-W. A., Arnott, W. P., Moosmüller, H., and Fung, K.: Equivalence of elemental carbon by thermal/optical reflectance and transmittance with different temperature protocols, Environ. Sci. Technol., 38, 4414-4422, https://doi.org/10.1021/es034936u, 2004.

Clarke, A., McNaughton, C., Kapustin, V., Shinozuka, Y., Howell, S., Dibb, J., Zhou, J., Anderson, B., Brekhovskikh, V., Turner, H., and Pinkerton, M.: Biomass burning and pollution aerosol over North America: Organic components and their influence on spectral optical properties and humidification response, J. Geophys. Res.-Atmos., 112, D12S18, https://doi.org/10.1029/2006jd007777, 2007.

Cross, E. S., Onasch, T. B., Ahern, A., Wrobel, W., Slowik, J. G., Olfert, J., Lack, D. A., Massoli, P., Cappa, C. D., Schwarz, J. P., Spackman, J. R., Fahey, D. W., Sedlacek, A., Trimborn, A., Jayne, J. T., Freedman, A., Williams, L. R., Ng, N. L., Mazzoleni, C., Dubey, M., Brem, B., Kok, G., Subramanian, R., Freitag, S., Clarke, A., Thornhill, D., Marr, L. C., Kolb, C. E., Worsnop, D. R., and Davidovits, P.: Soot Particle Studies - Instrument InterComparison - Project Overview, Aerosol Sci. Technol., 44, 592611, https://doi.org/10.1080/02786826.2010.482113, 2010.

Dastanpour, R., Momenimovahed, A., Thomson, K., Olfert, J., and Rogak, S.: Variation of the optical properties of soot as a function of particle mass, Carbon, 124, 201-211, https://doi.org/10.1016/j.carbon.2017.07.005, 2017.

Flowers, B. A., Dubey, M. K., Mazzoleni, C., Stone, E. A., Schauer, J. J., Kim, S.-W., and Yoon, S. C.: Optical-chemicalmicrophysical relationships and closure studies for mixed carbonaceous aerosols observed at Jeju Island; 3-laser photoacoustic spectrometer, particle sizing, and filter analysis, Atmos. Chem. Phys., 10, 10387-10398, https://doi.org/10.5194/acp-10-103872010, 2010.

Forestieri, S. and Cappa, C.: Measurement and modeling of the multi-wavelength optical properties of uncoated flame-generated soot: Data from the BC2, BC3, BC3+ and BC4 studies, UC Davis Dash, Dataset, https://doi.org/10.25338/B8JP4V, 2018.

Ghazi, R., Tjong, H., Soewono, A., Rogak, S. N., and Olfert, J. S.: Mass, Mobility, Volatility, and Morphology of Soot Particles Generated by a McKenna and
Inverted Burner, Aerosol Sci. Technol., 47, 395-405, https://doi.org/10.1080/02786826.2012.755259, 2013.

Hadley, O. L., Corrigan, C. E., and Kirchstetter, T. W.: Modified Thermal-Optical Analysis Using Spectral Absorption Selectivity To Distinguish Black Carbon from Pyrolized Organic Carbon, Environ. Sci. Technol., 42, 8459-8464, https://doi.org/10.1021/es800448n, 2008.

Hess, M., Koepke, P., and Schult, I.: Optical Properties of Aerosols and Clouds: The Software Package OPAC, B. Am. Meteorol. Soc., 79, 831-844, https://doi.org/10.1175/15200477(1998)079<0831:opoaac>2.0.co;2, 1998.

Hopkins, R. J., Tivanski, A. V., Marten, B. D., and Gilles, M. K.: Chemical bonding and structure of black carbon reference materials and individual carbonaceous atmospheric aerosols, J. Aerosol Sci., 38, 573-591, https://doi.org/10.1016/j.jaerosci.2007.03.009, 2007.

Huffman, J. A., Ziemann, P. J., Jayne, J. T., Worsnop, D. R., and Jimenez, J. L.: Development and characterization of a fast-stepping/scanning thermodenuder for chemically-resolved aerosol volatility measurements, Aerosol Sci. Technol., 42, 395407, https://doi.org/10.1080/02786820802104981, 2008.

Johansson, K. O., El Gabaly, F., Schrader, P. E., Campbell, M. F., and Michelsen, H. A.: Evolution of maturity levels of the particle surface and bulk during soot growth and oxidation in a flame, Aerosol Sci. Technol., 51, 1333-1344, https://doi.org/10.1080/02786826.2017.1355047, 2017.

Kahnert, M. and Devasthale, A.: Black carbon fractal morphology and short-wave radiative impact: a modelling study, Atmos. Chem. Phys., 11, 11745-11759, https://doi.org/10.5194/acp-1111745-2011, 2011.

Khalizov, A. F., Xue, H., Wang, L., Zheng, J., and Zhang, R.: Enhanced Light Absorption and Scattering by Carbon Soot Aerosol Internally Mixed with Sulfuric Acid, J. Phys. Chem. A, 113, 1066-1074, https://doi.org/10.1021/jp807531n, 2009.

Kirchstetter, T. W., Novakov, T., and Hobbs, P. V.: Evidence that the spectral dependence of light absorption by aerosols is affected by organic carbon, J. Geophys. Res.-Atmos., 109, D21208, https://doi.org/10.1029/2004jd004999, 2004.

Laborde, M., Mertes, P., Zieger, P., Dommen, J., Baltensperger, U., and Gysel, M.: Sensitivity of the Single Particle Soot Photometer to different black carbon types, Atmos. Meas. Tech., 5, 10311043, https://doi.org/10.5194/amt-5-1031-2012, 2012.

Lack, D. A., Lovejoy, E. R., Baynard, T., Pettersson, A., and Ravishankara, A. R.: Aerosol absorption measurement using photoacoustic spectroscopy: Sensitivity, calibration, and uncertainty developments, Aerosol Sci. Technol., 40, 697-708, https://doi.org/10.1080/02786820600803917, 2006.

Lack, D. A., Cappa, C. D., Covert, D. S., Baynard, T., Massoli, P., Sierau, B., Bates, T. S., Quinn, P. K., Lovejoy, E. R., and Ravishankara, A. R.: Bias in filter-based aerosol light absorption measurements due to organic aerosol loading: Evidence from ambient measurements, Aerosol Sci. Technol., 42, 1033-1041, https://doi.org/10.1080/02786820802389277, 2008.

Lack, D. A., Richardson, M. S., Law, D., Langridge, J. M., Cappa, C. D., McLaughlin, R. J., and Murphy, D. M.: Aircraft Instrument for Comprehensive Characterization of Aerosol Optical Properties, Part 2: Black and Brown Carbon Absorption and Absorption Enhancement Measured with Photo 
Acoustic Spectroscopy, Aerosol Sci. Technol., 46, 555-568, https://doi.org/10.1080/02786826.2011.645955, 2011.

Lambe, A. T., Ahern, A. T., Williams, L. R., Slowik, J. G., Wong, J. P. S., Abbatt, J. P. D., Brune, W. H., Ng, N. L., Wright, J. P., Croasdale, D. R., Worsnop, D. R., Davidovits, P., and Onasch, T. B.: Characterization of aerosol photooxidation flow reactors: heterogeneous oxidation, secondary organic aerosol formation and cloud condensation nuclei activity measurements, Atmos. Meas. Tech., 4, 445-461, https://doi.org/10.5194/amt-4445-2011, 2011.

Langridge, J. M., Richardson, M. S., Lack, D., Law, D., and Murphy, D. M.: Aircraft Instrument for Comprehensive Characterization of Aerosol Optical Properties, Part I: Wavelength-Dependent Optical Extinction and Its Relative Humidity Dependence Measured Using Cavity Ringdown Spectroscopy, Aerosol Sci. Technol., 45, 1305-1318, https://doi.org/10.1080/02786826.2011.592745, 2011.

Lohmann, U. and Feichter, J.: Global indirect aerosol effects: a review, Atmos. Chem. Phys., 5, 715-737, https://doi.org/10.5194/acp-5-715-2005, 2005.

López-Yglesias, X., Schrader, P. E., and Michelsen, H. A.: Soot maturity and absorption cross sections, J. Aerosol Sci., 75, 43-64, https://doi.org/10.1016/j.jaerosci.2014.04.011, 2014.

Mackowski, D. W. and Mishchenko, M. I.: Calculation of the $\mathrm{T}$ matrix and the scattering matrix for ensembles of spheres, J. Opt. Soc. Am. A, 13, 2266-2278, https://doi.org/10.1364/josaa.13.002266, 1996.

Massoli, P., Kebabian, P. L., Onasch, T. B., Hills, F. B., and Freedman, A.: Aerosol Light Extinction Measurements by Cavity Attenuated Phase Shift (CAPS) Spectroscopy: Laboratory Validation and Field Deployment of a Compact Aerosol Particle Extinction Monitor, Aerosol Sci. Technol., 44, 428-435, https://doi.org/10.1080/02786821003716599, 2010.

Medalia, A. I. and Heckman, F. A.: Morphology of aggregates - II. Size and shape factors of carbon black aggregates from electron microscopy, Carbon, 7, 567-582, https://doi.org/10.1016/00086223(69)90029-3, 1969.

Migliorini, F., Thomson, K., and Smallwood, G.: Investigation of optical properties of aging soot, Appl. Phys. B-Lasers O, 104, 273-283, https://doi.org/10.1007/s00340-011-4396-4, 2011.

Mullins, J. and Williams, A.: The optical properties of soot: a comparison between experimental and theoretical values, Fuel, 66, 277-280, https://doi.org/10.1016/0016-2361(87)90255-9, 1987.

Olofsson, N.-E., Simonsson, J., Török, S., Bladh, H., and Bengtsson, P.-E.: Evolution of properties for aging soot in premixed flat flames studied by laser-induced incandescence and elastic light scattering, Appl. Phys. B, 119, 669-683, https://doi.org/10.1007/s00340-015-6067-3, 2015.

Onasch, T. B., Trimborn, A., Fortner, E. C., Jayne, J. T., Kok, G. L., Williams, L. R., Davidovits, P., and Worsnop, D. R.: Soot Particle Aerosol Mass Spectrometer: Development, Validation, and Initial Application, Aerosol Sci. Technol., 46, 804-817, https://doi.org/10.1080/02786826.2012.663948, 2012.

Onasch, T. B., Fortner, E. C., Trimborn, A. M., Lambe, A. T., Tiwari, A. J., Marr, L. C., Corbin, J. C., Mensah, A. A., Williams, L. R., Davidovits, P., and Worsnop, D. R.: Investigations of SP-AMS Carbon Ion Distributions as a Function of Refractory Black Carbon Particle Type, Aerosol Sci. Technol., 49, 409-422, https://doi.org/10.1080/02786826.2015.1039959, 2015a.
Onasch, T. B., Massoli, P., Kebabian, P. L., Hills, F. B., Bacon, F. W., and Freedman, A.: Single Scattering Albedo Monitor for Airborne Particulates, Aerosol Sci. Technol., 49, 267-279, https://doi.org/10.1080/02786826.2015.1022248, 2015b.

Park, K., Cao, F., Kittelson, D. B., and McMurry, P. H.: Relationship between Particle Mass and Mobility for Diesel Exhaust Particles, Environ. Sci. Technol., 37, 577-583, https://doi.org/10.1021/es025960v, 2003.

Purcell, E. M. and Pennypacker, C. R.: Scattering and absorption of light by nonspherical dielectric grains, Astrophys. J., 186, 705714, https://doi.org/10.1086/152538, 1973.

Radney, J. G., You, R., Ma, X., Conny, J. M., Zachariah, M. R., Hodges, J. T., and Zangmeister, C. D.: Dependence of Soot Optical Properties on Particle Morphology: Measurements and Model Comparisons, Environ. Sci. Technol., 48, 3169-3176, https://doi.org/10.1021/es4041804, 2014.

Ramanathan, V. and Carmichael, G.: Global and regional climate changes due to black carbon, Nat. Geosci., 1, 221-227, https://doi.org/10.1038/ngeo156, 2008.

Saliba, G., Subramanian, R., Saleh, R., Ahern, A. T., Lipsky, E. M., Tasoglou, A., Sullivan, R. C., Bhandari, J., Mazzoleni, C., and Robinson, A. L.: Optical properties of black carbon in cookstove emissions coated with secondary organic aerosols: Measurements and modeling, Aerosol Sci. Technol., 50, 1264-1276, https://doi.org/10.1080/02786826.2016.1225947, 2016.

Scarnato, B. V., Vahidinia, S., Richard, D. T., and Kirchstetter, T. W.: Effects of internal mixing and aggregate morphology on optical properties of black carbon using a discrete dipole approximation model, Atmos. Chem. Phys., 13, 5089-5101, https://doi.org/10.5194/acp-13-5089-2013, 2013.

Schnaiter, M., Horvath, H., Mohler, O., Naumann, K. H., Saathoff, H., and Schock, O. W.: UV-VIS-NIR spectral optical properties of soot and soot-containing aerosols, J. Aerosol Sci., 34, 14211444, https://doi.org/10.1016/s0021-8502(03)00361-6, 2003.

Schnaiter, M., Gimmler, M., Llamas, I., Linke, C., Jäger, C., and Mutschke, H.: Strong spectral dependence of light absorption by organic carbon particles formed by propane combustion, Atmos. Chem. Phys., 6, 2981-2990, https://doi.org/10.5194/acp-6-29812006, 2006.

Schwarz, J. P., Gao, R. S., Spackman, J. R., Watts, L. A., Thomson, D. S., Fahey, D. W., Ryerson, T. B., Peischl, J., Holloway, J. S., Trainer, M., Frost, G. J., Baynard, T., Lack, D. A., de Gouw, J. A., Warneke, C., and Del Negro, L. A.: Measurement of the mixing state, mass, and optical size of individual black carbon particles in urban and biomass burning emissions, Geophys. Res. Lett., 35, L13810, https://doi.org/10.1029/2008GL033968, 2008.

Sharma, N., Arnold, I. J., Moosmüller, H., Arnott, W. P., and Mazzoleni, C.: Photoacoustic and nephelometric spectroscopy of aerosol optical properties with a supercontinuum light source, Atmos. Meas. Tech., 6, 3501-3513, https://doi.org/10.5194/amt6-3501-2013, 2013.

Slowik, J. G., Cross, E. S., Han, J.-H., Davidovits, P., Onasch, T. B., Jayne, J. T., Williams, L. R., Canagaratna, M. R., Worsnop, D. R., Chakrabarty, R. K., Moosmueller, H., Arnott, W. P., Schwarz, J. P., Gao, R.-S., Fahey, D. W., Kok, G. L., and Petzold, A.: An inter-comparison of instruments measuring black carbon content of soot particles, Aerosol Sci. Technol., 41, 295314, https://doi.org/10.1080/02786820701197078, 2007. 
Sorensen, C. M.: Light Scattering by Fractal Aggregates: A Review, Aerosol Sci. Technol., 35, 648-687, https://doi.org/10.1080/02786820117868, 2001.

Sorensen, C. M.: The Mobility of Fractal Aggregates: A Review, Aerosol Sci. Technol., 45, 765-779, https://doi.org/10.1080/02786826.2011.560909, 2011.

Stier, P., Seinfeld, J. H., Kinne, S., and Boucher, O.: Aerosol absorption and radiative forcing, Atmos. Chem. Phys., 7, 5237-5261, https://doi.org/10.5194/acp-7-5237-2007, 2007.

Stipe, C. B., Higgins, B. S., Lucas, D., Koshland, C. P., and Sawyer, R. F.: Inverted co-flow diffusion flame for producing soot, Rev. Sci. Instrum., 76, 023908, https://doi.org/10.1063/1.1851492, 2005.

Wang, R., Balkanski, Y., Boucher, O., Ciais, P., Schuster, G. L., Chevallier, F., Samset, B. H., Liu, J., Piao, S., Valari, M., and Tao, S.: Estimation of global black carbon direct radiative forcing and its uncertainty constrained by observations, J. Geophys. Res.-Atmos., 121, 5948-5971, https://doi.org/10.1002/2015JD024326, 2016.
Wu, J.-S., Krishnan, S., and Faeth, G.: Refractive indices at visible wavelengths of soot emitted from buoyant turbulent diffusion flames, J. Heat Transf., 119, 230-237, https://doi.org/10.1115/1.2824213, 1997.

You, R., Radney, J. G., Zachariah, M. R., and Zangmeister, C. D.: Measured Wavelength-Dependent Absorption Enhancement of Internally Mixed Black Carbon with Absorbing and Nonabsorbing Materials, Environ. Sci. Technol., 50, 7982-7990, https://doi.org/10.1021/acs.est.6b01473, 2016.

Zhang, R., Khalizov, A. F., Pagels, J., Zhang, D., Xue, H., and McMurry, P. H.: Variability in morphology, hygroscopicity, and optical properties of soot aerosols during atmospheric processing, P. Natl. Acad. Sci. USA, 105, 10291-10296, https://doi.org/10.1073/pnas.0804860105, 2008. 